Department of Ophthalmology, University of Helsinki, Helsinki, and

Rheumatism Foundation Hospital, Heinola, Finland

\title{
Uveitis in Juvenile Idiopathic Arthritis
}

\section{Kaisu Kotaniemi}

Academic Dissertation

To be presented with the permission of the Medical Faculty of the University of Helsinki, for public examination, in the Auditorium of the Department of Ophthalmology, Haartmaninkatu $4 \mathrm{C}$, Helsinki, On October 12th, 2001, at 12:00 noon

Helsinki 2001 


\author{
Supervised by: \\ Professor Kimmo Aho, MD, PhD \\ National Public Health Institute, Helsinki \\ and \\ Docent Anni Karma, MD, PhD \\ Department of Ophthalmology, \\ Helsinki University Hospital, Helsinki
}

Reviewed by

Docent Kaija Tuppurainen, MD, PhD

Department of Ophthalmology,

Kuopio University Hospital, Kuopio

and

Docent Pekka Hannonen, MD, PhD

Department of Internal Medicine,

Central Hospital of Central Finland, Jyväskylä

Discussed with

Professor (Emeritus) Ahti Tarkkanen, MD, PhD

Department of Ophthalmology,

Helsinki University Hospital, Helsinki, Finland

ISBN 952-91-3871-7 (nid.)

ISBN 952-10-0146-1 (verkkojulkaisu, pdf)

http://ethesis.helsinki.fi

Helsinki 2001

Yliopistopaino 
To Antero, Anne, Laura, and Miika 


\section{ABSTRACT}

The purpose of the present study was to extend our knowledge of the occurrence, characteristics and prognosis of uveitis in patients with juvenile idiopathic arthritis (JIA: arthritis of unknown cause of at least six weeks' duration in a child under 16 years of age).

The occurrence of uveitis was examined retrospectively in subjects entitled under the nationwide sickness insurance scheme to receive specially reimbursed medication for JIA in 5/21 central hospital districts in Finland (population basis about 1300000 inhabitants) during 1980, 1985 and 1990. A total of 114 children with JIA were found and uveitis was diagnosed in $16 \%$ of them. Uveitis was chronic (duration $>6$ months) in nine cases, the most severe cases being those three in whom uveitis was detected at the onset of arthritis.

In 49 sibling pairs with JIA from the Rheumatism Foundation Hospital uveitis was detected in $26 \%$. These 80 familial JIA cases belonging to 37 families with two or three affected siblings were collected from about 2000 children seen at the Hospital during 15 years. The observed concordance rate for uveitis (three pairs) did not differ from that expected (3.4 pairs). Uveitis was chronic in most instances, but its course was usually mild.

In the clinic-based cohort of 426 patients with newly diagnosed JIA from the Rheumatism Foundation Hospital the most important determinants of associated uveitis were early onset of arthritis (at the age of 2 to 4 years) and antinuclear antibody (ANA) positivity. During the mean follow-up time of 4.5 years a total of 104 (24\%) children with JIA developed uveitis. The condition was in most cases (99 out of 104) asymptomatic and was found early in the disease process, in a majority of cases during the first four years from the onset of arthritis. Proportionally uveitis was as frequent in rheumatoid factor-seronegative polyarthritis as in oligoarthritis and there was no predominance of girls. The prognosis of uveitis in this prospective series was better than that in most earlier reports; complications in $24 \%$ of cases, none of the patients became blind.

In the above cohort, 372 children had seronegative oligoarthritis or polyarthritis. Within this group, the activity of arthritis was compared between patients with associated uveitis and 
without it. The erythrocyte sedimentation rate was significantly higher at the diagnosis of arthritis and at the end of follow-up in 96 JIA patients with uveitis than in the 276 without. The hemoglobin value was significantly lower at the diagnosis of arthritis in patients with uveitis, but not at the end of follow-up. The number of inflamed joints was significantly greater at the end of the follow-up in patients with persistent polyarthritis and uveitis compared to those polyarthritis patients without uveitis. Patients with uveitis were significantly more often treated with oral prednisolone, glucocorticoid injections and methotrexate compared to patients without uveitis. Clinical remission of arthritis was achieved significantly less frequently in patients with uveitis than in those without. The inflammatory activity of arthritis would thus appear to be increased in patients with JIA and uveitis compared to those without uveitis.

A report of a patient with juvenile-type chronic polyarthritis and late-onset severe chronic uveitis controlled with prednisolone, cyclosporin A and methotrexate is included in the series. The successful treatment was carried out in close co-operation with rheumatologists.

In a study based on the Finnish Register of Visual Impairment arthritis or a comparable condition was found as the etiology in $22 \%$ of the 174 patients with severe uveitis leading to visual impairment during 1980-1996. The greatest single group in this series comprised patients with JIA, 8\%, followed by spondyloarthropathy 6\%, sarcoidosis $3 \%$ and seronegative rheumatoid arthritis 2\%. Legally specified blindness was documented in 65 of 174 patients, including eight persons totally blind. Overall, uveitis led to visual impairment within a mean period of 18 years.

In some patients the treatment of chronic uveitis associated with JIA is difficult, and in such cases the collaboration of ophthalmologists and pediatric rheumatologists/rheumatologists is essential in determining the optimal management early in the disease course. 


\section{CONTENTS}

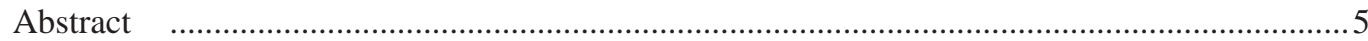

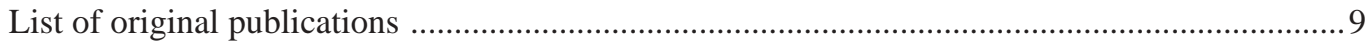

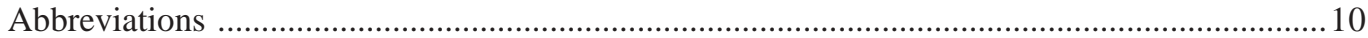

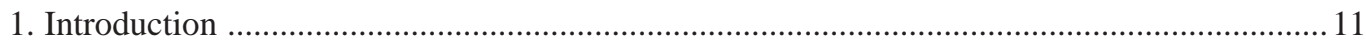

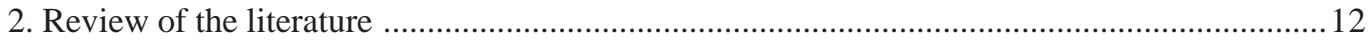

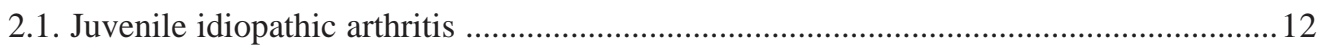

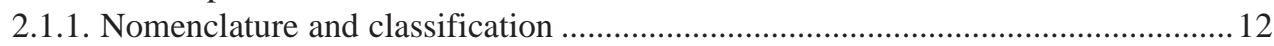

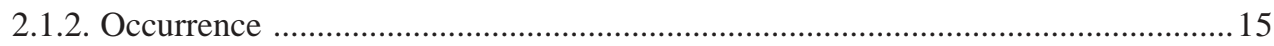

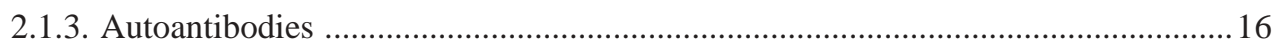

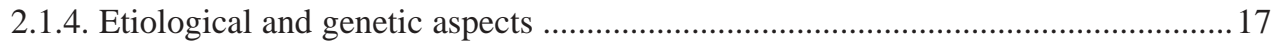

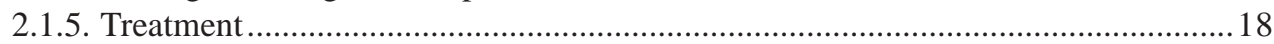

2.1.6. Course of juvenile idiopathic arthritis in the main subgroups .............................. 19

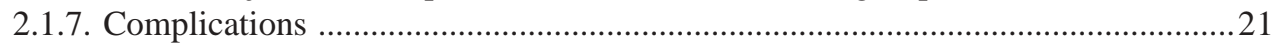

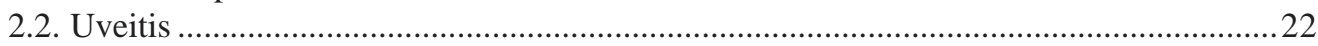

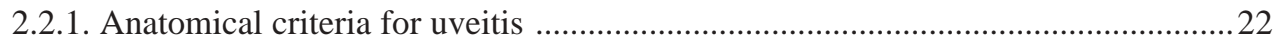

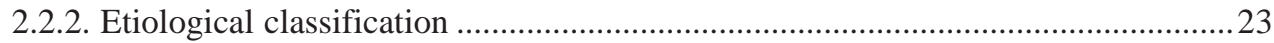

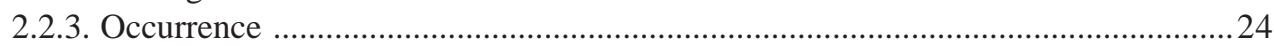

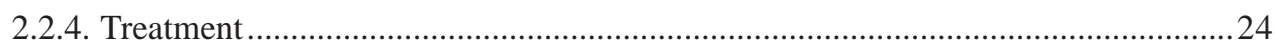

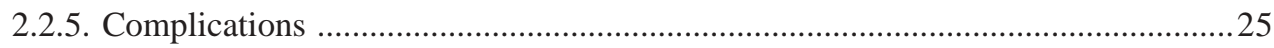

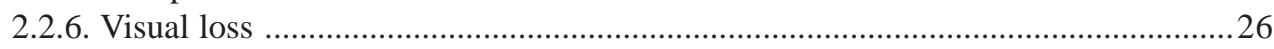

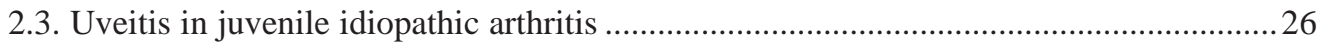

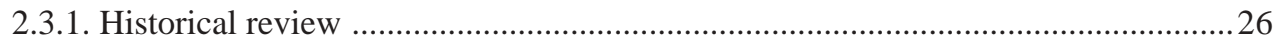

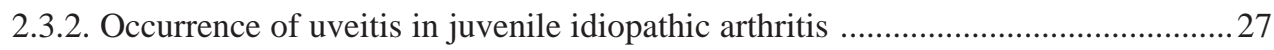

2.3.3. Clinical picture of uveitis in juvenile idiopathic arthritis ....................................29

2.3.4. Characteristics of uveitis patients in juvenile idiopathic arthritis ........................... 30

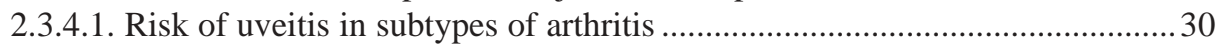

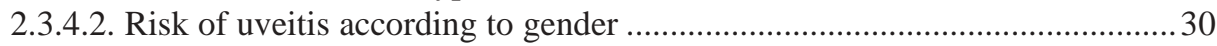

2.3.4.3. Onset of uveitis in relation to age of child and onset of arthritis .................. 30

2.3.4.4. Genetic factors in juvenile idiopathic arthritis with uveitis ............................. 31

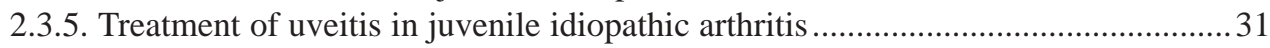

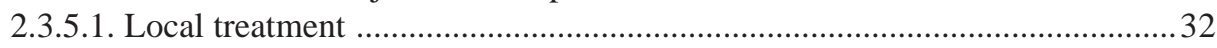

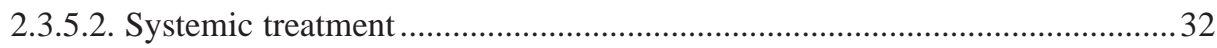

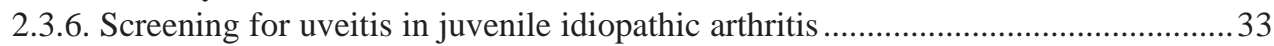

2.3.7. Prognosis of uveitis in juvenile idiopathic arthritis .............................................. 33

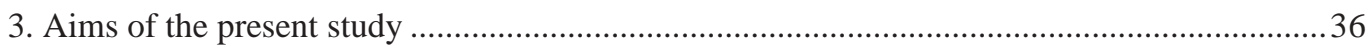

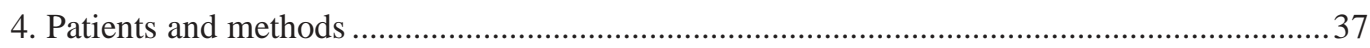

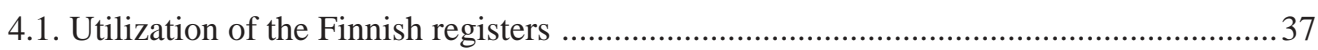

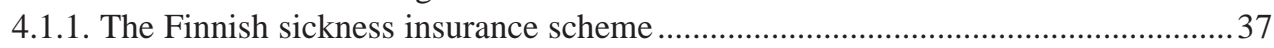

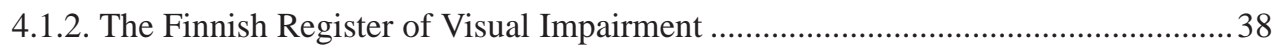

4.2. Patients with juvenile idiopathic arthritis from the Rheumatism Foundation Hospital .. 39

4.2.1. Diagnosis of juvenile idiopathic arthritis and follow-up of patients ...................... 41 
4.2.2. Ophthalmologic examination, treatment and follow-up of uveitis

5. Results

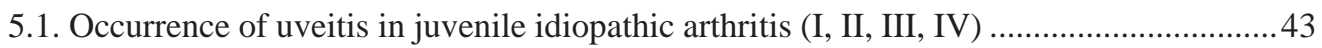

5.1.1. Late-onset uveitis in juvenile-type chronic polyarthritis - a case report (I) ............43

5.1.2. Population-based occurrence of uveitis in juvenile idiopathic arthritis (II) ............43

5.1.3. Occurrence of uveitis in sibling pairs with juvenile idiopathic arthritis (III) .........45

5.1.4. Occurrence of uveitis in recently diagnosed juvenile idiopathic arthritis (IV) .......47

5.2. Uveitis as a marker of active arthritis in 372 patients with juvenile idiopathic

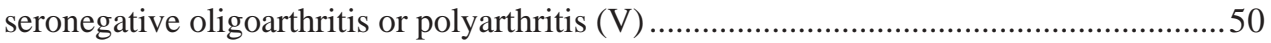

5.3. Uveitis as a cause of visual loss in arthritides and comparable conditions (VI) .............52

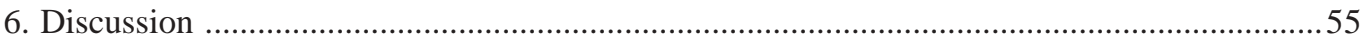

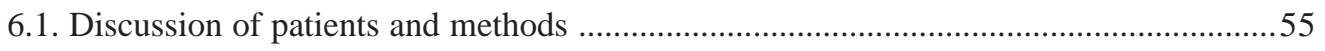

6.1.1. Genetic background of the Finnish population .....................................................55

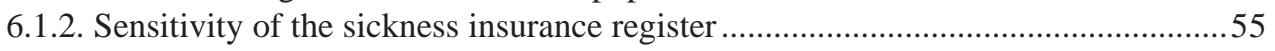

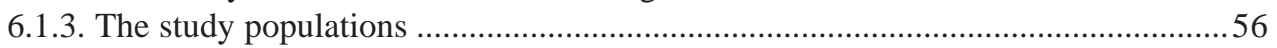

6.1.3.1. Population-based study of uveitis in juvenile idiopathic arthritis .................56

6.1.3.2. Uveitis in patients with a recent diagnosis of juvenile idiopathic arthritis ...56

6.1.3.3. Uveitis in sibling pairs with juvenile idiopathic arthritis .............................56

6.1.3.4. Uveitis as a cause of visual loss in arthritides and comparable conditions ...57

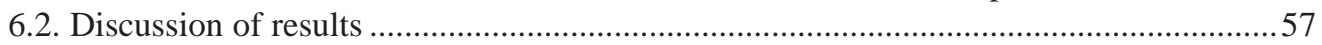

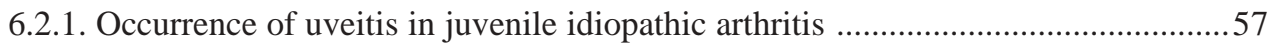

6.2.2. Determinants associated with development of uveitis in juvenile idiopathic

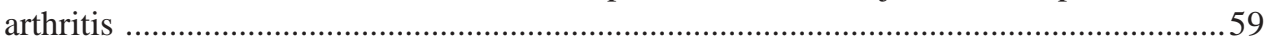

6.2.3. Complications and treatment of uveitis in juvenile idiopathic arthritis ...................60 60

6.2.4. Association of uveitis and arthritis in juvenile idiopathic arthritis .........................62 62

6.2.5. Uveitis as a cause of visual loss in arthritides and comparable conditions .............63

7. Recommendations concerning the screening and management of uveitis associated with

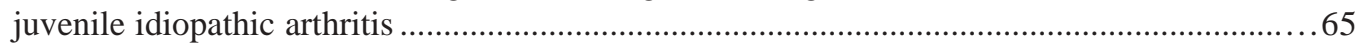

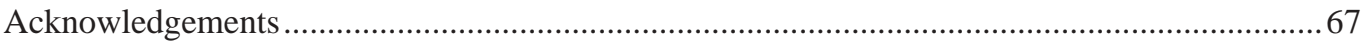

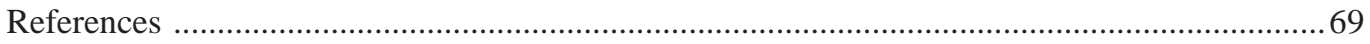

Original publications I to VI 


\section{LIST OF ORIGINAL PUBLICATIONS}

I. K. Kotaniemi: Late onset uveitis in juvenile-type chronic polyarthritis controlled with prednisolone, cyclosporin A and methotrexate. Clin Exp Rheumatol 1998;16:469-471.

II. K. Kotaniemi, O. Kaipiainen-Seppänen, A. Savolainen, A. Karma: A population-based study on uveitis in juvenile rheumatoid arthritis. Clin Exp Rheumatol 1999;17:119-122.

III. H. Säilä, K. Kotaniemi, A. Savolainen, H. Kautiainen, M. Leirisalo-Repo, K. Aho: Uveitis in sibling pairs with juvenile idiopathic arthritis. Rheumatology 2001;40:221-4.

IV. K. Kotaniemi, H. Kautiainen, A. Karma, K. Aho: Occurrence of uveitis in recently diagnosed juvenile chronic arthritis. A prospective study. Ophthalmology, in press.

V. K. Kotaniemi, A. Kotaniemi, A. Savolainen: Uveitis as a marker of active arthritis in 372 patients with juvenile idiopathic seronegative oligoarthritis or polyarthritis. Clin Exp Rheumatol, in press.

VI. K. Kotaniemi, K. Aho, A. Kotaniemi: Uveitis as a cause of visual loss in arthritides and comparable conditions. J Rheumatol 2001;28:309-12. 


\section{ABBREVIATIONS}

AAU Acute anterior uveitis

ANA Antinuclear antibodies

ARA American Rheumatism Association

CAU Chronic anterior uveitis

CI Confidence interval

CME Cystoid macular edema

CRP C-reactive protein

ESR Erythrocyte sedimentation rate

EULAR European League Against Rheumatism

FAG Fluorescein angiography

$\mathrm{Hb}$ Hemoglobin value

HLA Human leukocyte antigen

IBD Inflammatory bowel disease

IgG Immunoglobulin $\mathrm{G}$

ILAR International League of Against Rheumatism

IUSG International Uveitis Study Group

JAS Juvenile ankylosing spondylitis

JCA Juvenile chronic arthritis

JIA Juvenile idiopathic arthritis

JPsA Juvenile psoriatic arthropathy

JRA Juvenile rheumatoid arthritis

NSAID Non-steroidal anti-inflammatory drug

RA Rheumatoid arthritis

RF Rheumatoid factor

SD Standard deviation

SPA Spondyloarthropathy

UCLA University of California Los Angeles 


\section{INTRODUCTION}

Juvenile idiopathic arthritis (JIA) is defined as an arthritis of unknown cause of at least six weeks' duration commencing before the 16th birthday (Petty and Southwood 1998). Several subgroups of JIA are well recognised, differing according to clinical manifestations, prognosis, specific autoimmune features and genetic determinants. The three major subgroups distinguished during the first six months of arthritis are oligoarthritis (1 to 4 joints involved), polyarthritis ( $\geq 5$ joints afflicted), and systemic onset JIA (with fever and papulomacular rash at the onset).

Ethnic differences exist with regard to occurrence rates and distributions according to subgroups and gender. In Western societies the annual incidence of JIA is 10-20/100 000 in the pediatric population. Mono- and pauciarticular types of onset predominate, comprising about 50 to $75 \%$ of these patients. The proportion of polyarthritis is estimated to be 20 to $40 \%$. Systemic onset JIA is less common; it is detected in 3 to $10 \%$. The variation in the proportions of the different subgroups depends in part on the study material: population- or clinic-based. Children with JIA are frequently positive for antinuclear antibodies (ANA).

A frequent extra-articular manifestation of JIA is chronic asymptomatic uveitis, which is found in about $20 \%$ of children with JIA during the first seven years of the disease. The risk of insidious uveitis is greatest in ANA-positive girls with early onset oligoarthritis. The male:female ratio in patients with JIA-associated uveitis is about 1:5. The routine screening of JIA patients 2 to 4 times a year for the detection of silent uveitis was recommended three decades ago. Although the prognosis of uveitis is improving, due to prompt treatment with topical corticosteroids and mydriatics and in severe cases with immunosuppressive agents and to advances in surgical treatment of complications (cataract and glaucoma), 6 to $12 \%$ of these children nevertheless become visually handicapped (Kanski 1990). A great challenge to ophthalmologists and pediatric rheumatologists is how to save the sight of these children (Nguyen and Foster 1998).

The impulse to the present study arose from everyday work among children with JIA-associated uveitis: to widen our knowledge of its occurrence, characteristics and prognosis. 


\section{REVIEW OF THE LITERATURE}

\subsection{Juvenile idiopathic arthritis}

\subsubsection{Nomenclature and classification}

George Frederic Still published his classic description of chronic arthritis in children in 1897 (Still 1897). In the early years juvenile arthritis was called Still's disease; nowadays this term is reserved and sometimes used for the systemic form of JIA and also for the similar systemic arthritis starting in rare cases in adulthood (Wood 1978, Andersson Gäre 1999).

The term juvenile idiopathic arthritis is used for persistent joint inflammation or systemic illness with fever and rash of unknown cause lasting at least six weeks and starting in a child under 16 years of age (Petty and Southwood 1998). The criteria of the European League Against Rheumatism (EULAR) (Wood 1978) are widely applied in Europe and the disease is named juvenile chronic arthritis, whereas in the United States idiopathic childhood arthritis is called juvenile rheumatoid arthritis according to the American Rheumatism Association's (ARA, nowadays named the American College of Rheumatism, ACR) criteria (Brewer et al 1977). Recently, a new set of criteria was published by the International League Against Rheumatism (ILAR), covering all idiopathic childhood arthritides under the name of juvenile idiopathic arthritis (Petty and Southwood 1998).

The three main sets of criteria for childhood chronic arthritis of unknown cause are presented in Table 1. In the present work the term JIA was used throughout, although in some instances this will result in minor discrepancies. 
Table 1. The three main sets of criteria for childhood chronic arthritis

\begin{tabular}{|c|c|c|c|}
\hline & EULAR & ARA & ILAR \\
\hline Name for the disease group & $\begin{array}{l}\text { Juvenile chronic } \\
\text { arthritis (JCA) }\end{array}$ & $\begin{array}{l}\text { Juvenile rheumatoid } \\
\text { arthritis (JRA) }\end{array}$ & $\begin{array}{l}\text { Juvenile idiopathic } \\
\text { arthritis (JIA) }\end{array}$ \\
\hline JAS, JPsA, IBD & $\begin{array}{c}\text { included } \\
\text { (separately listed) }\end{array}$ & excluded & included \\
\hline $\begin{array}{l}\text { Duration of joint symptoms } \\
\text { necessary for the diagnosis of } \\
\text { arthritis }\end{array}$ & 3 months & 6 weeks & 6 weeks \\
\hline $\begin{array}{l}\text { Age of the patient at disease } \\
\text { onset }\end{array}$ & $0-15$ years & $0-15$ years & $0-15$ years \\
\hline Exclusion of other diseases & yes & yes & yes \\
\hline $\begin{array}{l}\text { Definition of subtypes at } 6 \\
\text { months' disease duration }\end{array}$ & yes & yes & yes \\
\hline
\end{tabular}

Abbreviations: JAS, juvenile ankylosing spondylitis; JPsA, juvenile psoriatic arthropathy;

IBD, arthropathy associated with inflammatory bowel disease.

According to the ILAR criteria, JIA is divided into seven subtypes after six months' disease duration:

Pauciarthritis (also named oligoarthritis), involving 1 to 4 joints, is the most common type of JIA, comprising 50 to $70 \%$ of JIA patients; pauciarthritis is further divided into persistent pauciarticular arthritis and extended oligoarthritis, i.e. arthritis with pauciarticular onset and polyarticular course.

In polyarthritis five or more joints are inflamed; the condition comprises rheumatoid factor (RF)-negative and RF-positive polyarthritis; 20 to $40 \%$ of JIA cases belong to the polyarthritis group and the great majority of these are RF-negative.

Systemic onset-type JIA is diagnosed in about 3 to $10 \%$ of JIA patients. It initially manifests with fever and typical papulomacular rash; subsequently the children develop arthritis. 
Enthesitis-related arthritis patients are often boys of the age of 10 or over, in many cases HLA B27- positive; they may have acute anterior uveitis (AAU) and may later develop a disease resembling adult spondyloarthropathy.

Psoriatic arthritis presents with typical psoriatic skin and/or nail involvement and joint symptoms.

Other types of arthritis include for example arthropathy associated with inflammatory bowel diseases (Petty and Southwood 1998).

The division of the disease into distinct subgroups is relevant in that these differ in their course and prognosis, and probably also in their etiological background. JIA is not limited to the joints; patients may have a variety of extra-articular manifestations. In the systemic type of JIA the general symptoms predominate, especially at the onset of the disease. Fever, often of lesser degree, is also a common feature in the other subtypes; in addition, lymphadenopathy, pericarditis and anemia are seen. Uveitis is nevertheless the most common extra-articular manifestation of JIA (John and John 1984, Cassidy et al 1989).

Two different kinds of uveitis are detected in JIA: AAU, which frequently accompanies HLA B27-associated disease, and insidious chronic anterior uveitis (CAU), which occurs most frequently in ANA- positive girls with early-onset oligoarthritis (beginning of arthritis before the age of eight years).

The main characteristics of patients belonging to the most common onset types of JIA are shown in Table 2 (John and John 1984, Cassidy et al 1989, Cassidy 1993). 
Table 2. Specific characteristics of patients in the main onset types of juvenile idiopathic arthritis

\begin{tabular}{lccc}
\hline & Oligoarthritis & Polyarthritis & Systemic onset arthritis \\
\hline Number of joints involved & $<5$ & $\geq 5$ & variable \\
Sex ratio (male/female) & $1: 4$ & $1: 3$ & $1: 1$ \\
Chronic uveitis & $20 \%$ & $5 \%$ & rare \\
ANA-positive & $50 \%$ & $20 \%$ & $10 \%$ \\
RF-positive & rare & $15 \%$ & rare \\
\hline
\end{tabular}

\subsubsection{Occurrence}

The published data on the incidence and prevalence of JIA are somewhat difficult to compare by reason of the heterogeneity of the disease, differences in the classification criteria, the nature of the study material, and case ascertainment. Ethnic and geographical factors as well as seasonal variations in the occurrence of JIA have been observed (Andersson Gäre et al 1987, Andersson Gäre and Fasth 1992, Oen and Cheang 1996, Andersson Gäre 1999).

The prevalence of JIA in areas where reliable data are available has been estimated to be about $0.1 \%$ in the pediatric population, and its annual incidence has varied from 10 to 20/100 000 (Towner et al 1983, Kunnamo et al 1986, Oen and Cheang 1996, Andersson Gäre 1999). The incidence studies from Europe and North America predominantly involve populations of North European ancestry. The highest reported rates are from the Scandinavian countries and a tendency toward a falling north- to south gradient has been noted in Europe (Andersson Gäre 1999). No such gradient seems to exist in North America.

Recently, a JIA incidence of 14/100 000 was reported in the Finnish pediatric population <16 years old (Kaipiainen-Seppänen and Savolainen 1996). Accordingly, it can be estimated that there are about 150 new cases of JIA in Finland each year. In different community-based studies from Finland, 66 to $76 \%$ of children with JIA have been found to have oligoarthritis, 18 to $31 \%$ polyarthritis, and only 3 to $6 \%$ systemic onset JIA (Lantto and von Wendt 1985, Kunnamo et al 1986, Kaipiainen-Seppänen and Savolainen 1996). 


\subsubsection{Autoantibodies}

Many immunological abnormalities have been found in children with various forms of chronic arthritis, but few are clinically useful or well understood (Leak 1988, Lawrence et al 1993). It is important, however, to distinguish patients with ANA and RF.

The most common immunological abnormality in JIA is positive ANA, which usually exhibits a homogeneous or speckled pattern in the indicator cell. The frequency of positive reactions depends on the test techniques adopted. On average, ANA has been detected by immunofluorescence in roughly $30 \%$ of children with JIA, most frequently in patients with oligoarthritis, less so in those with RF-negative polyarthritis and only seldom in the other subtypes of JIA. Interestingly, ANA-positive patients have a clearly increased risk of uveitis (Leak et al 1986). The underlying reason for this association is not known.

Specific components of nuclei have been identified as the antigens for the ANA reaction in patients with systemic lupus erythematosus and certain other systemic rheumatic diseases. Antibodies against these components do not occur in patients with JIA; the nature of the antigen(s) responsible for positive ANA in JIA patients has not yet been settled with any certainty (Leak 1988, Lawrence et al 1993).

RF as determined by conventional test techniques occurs only seldom in patients with JIA. Those children who do have a persistent high-titred RF quite obviously have genuine rheumatoid arthritis (RA), which has its onset in childhood. Attention has been drawn to the occurrence of so-called hidden RF, i.e. RF blocked by autologous immunoglobulin $\mathrm{G}$ ( $\operatorname{IgG}$ ), in other forms of JIA (Lawrence et al 1993), but there seems to be no unanimity as to the validity of these findings.

In patients with RA a number of other autoantibody systems are present which have been claimed to be specific enough to serve as diagnostic and prognostic markers of this disease (Goldbach-Mansky et al 2000). Very little information is available concerning the occurrence of these marker antibodies in JIA. 
Autoantibodies against soluble bovine retinal S protein may be linked to ocular damage in patients with JIA, since children with JIA-associated uveitis have been reported to have higher antibody levels compared to those without eye disease and to normal controls (Petty et al 1987).

\subsubsection{Etiological and genetic aspects}

As pointed out above (2.1.1.), the term JIA covers a number of different disease entities. RFpositive polyarthritis, psoriatic arthritis and enthesitis-related arthritis have their counterparts among adults (2.1.6.). The risk factors and the genetic background of these entities will not be discussed in this review.

The subtypes of JIA occurring predominantly and also most frequently in children are systemic arthritis, oligoarthritis and RF-negative polyarthritis. As previously pointed out, systemic arthritis may occur in adults (adult-onset Still's disease) and a genetic link has been proposed between JIA and adult RF-negative polyarthritis (Gao et al 1991). The latter observation may be taken to mean that some cases of adult RF-negative RA represent an adult counterpart to juvenile polyarthritis.

Substantial variation in the occurrence of JIA over extended (secular trends) and shorter (seasonal variation) periods has been described in some studies (Andersson Gäre 1999, Glass and Giannini 1999), suggesting the implication of environmental triggers. Even more clear-cut clusters have been reported, particularly in one study from England in which there was an accumulation of JIA cases associated with influenza A infection (Pritchard et al 1988). In Finland, the incidence of JIA remained the same during the years 1980, 1985 and 1990, whereas a significant increase in number of cases and their spatial clustering was noted in 1995 (Kaipiainen-Seppänen and Savolainen 2001). In this regard it is worth noting that the epidemic of Lyme arthritis in Connecticut was initially regarded as an unusual cluster of JIA (Steere et al 1977).

Some family aggregation and a few monozygotic twin pairs concordant for JIA have been described (Silman and Hochberg 1993, Glass and Giannini 1999), suggesting the involvement of genetic factors. Since, however, virtually no information is available regarding the basic JIA population from which these cases were derived, it is not possible to draw conclusions concerning the magnitude of the genetic component. Very recently, 41 multicase families with 
88 siblings afflicted with JIA were found in a Finnish patient population of about 2000 (Savolainen et al 2000). In view of the population prevalence of the disease (1 per 1000), the figures would indicate that the sibling recurrence ratio (probably the best indicator of the magnitude of the genetic component) is fairly high, certainly higher than in adult RA.

Accumulating data indicate significant associations between particular HLA (human leukocyte antigen) alleles and certain forms of JIA (Donn and Ollier 1996, Glass and Giannini 1999). There may be difficulties in comparison of different studies; e.g. patient inclusion criteria have not been uniform. Certain general conclusions can be drawn:

a) The HLA allele distributions differ between patients with systemic disease, oligoarthritis and RF negative polyarthritis.

b) Several different alleles can be involved. In some instances this is due to close linkage of the alleles, but totally independent susceptibility alleles may equally exist.

c) The HLA alleles operating in JIA can contribute to an increased risk only during a certain age interval and be neutral or even protective at other times (Murray et al 1999).

d) There may be ethnic differences in HLA associations.

The relative risk conferred by certain HLA allele combinations can be quite high. Nonetheless the established HLA associations explain merely a part, perhaps only a small part, of the overall genetic background of JIA. Progress in molecular genetics has provided means for genome wide screening, offering prospects to identifying new susceptibility loci outside the HLA region ( Glass and Giannini 1999).

\subsubsection{Treatment}

Treatment of JIA is multidisciplinary (orthopedics, physiotherapy etc.) but the study described here concentrates on drug therapy. The immediate purpose of treatment is to control the disease and the ultimate goal is to prevent disability and premature death.

Nonsteroidal anti-inflammatory drugs (NSAIDs) together with intra-articular corticosteroid injections are widely used at the onset of arthritis. Of disease modifying antirheumatic drugs, hydroxychloroquine, gold salts and sulfasalazine alone or in combinations are included in the treatment regimen if NSAIDs are not sufficiently effective. During the last 10 years gold has frequently been replaced by methotrexate. In refractory cases of arthritis and uveitis the 
treatment is reinforced by corticosteroids, other immunosuppressive or immunomodulatory drugs such as cyclosporine and azathioprine. Rarely, even chlorambucil and cyclophosphamide are considered for medication in the most severe cases, above all in amyloidosis (Rosenbaum 1994, Savolainen and Ylijoki 1995, Savolainen 1999). Local treatment with intra-articular steroid injections plays a central role in current practice in pediatric arthritis and is safe and effective (Cassidy 1993).

Once remission is achieved, the medication is gradually tapered down over a period of months and years and the treatment is discontinued drug by drug, taking into account the clinical status of the child.

\subsubsection{Course of juvenile idiopathic arthritis in the main subgroups}

As mentioned above, the most common subtype of JIA is oligoarthritis, also called pauciarthritis. It affects mainly girls and has its peak incidence at the age of three years. The joints usually involved are knees, wrists and ankles, including subtalar joints. In one third or a half of patients the joint inflammation begins in one single joint. This type of JIA is commonly associated with uveitis, and ANA-positivity is a frequent finding. The articular prognosis in this disease subtype is often good; remission frequently occurs in 4 to 5 years (Cassidy 1993, Woo and Wedderburn 1998). Uveitis is common, occurring in about $20 \%$ of these children and consequently worsening the prognosis (Kanski and Petty 1996).

If oligoarthritis eventually spreads to more than four joints it is termed extended oligoarthritis. This form of arthritis is often clinically indistinguishable from polyarthritis, and has the same kind of prognosis as polyarthritis (Cassidy et al 1986, Flat $\phi$ et al 1998). Methotrexate has been shown to be an effective treatment in these cases.

$R F$-negative polyarthritis is often insidious at onset, with gradual development of progressive joint involvement. Large joints, typically knees, wrists, elbows and ankles are frequently first afflicted, but also the small joints in hands or feet can be involved, either early or late during the disease course. The pattern of joint involvement is often symmetric. An affection of the cervical spine occurs in half of the children with polyarticular JIA. Systemic manifestations of this subtype include low-grade fever, hepatosplenomegaly and lymphadenopathy. Chronic uveitis is found in about 5\% of cases (Cassidy 1993, Kanski and Petty 1996, Woo and Wedderburn 1998). 
RF-positive polyarthritis typically occurs in teenagers and can lead to widespread joint destruction. It is fairly rare, comprising about $3 \%$ of JIA patients in the UK and Finland. It is most likely RF-positive RA, having its onset at pediatric age, and uveitis occurs rarely in this subtype of JIA (Cassidy 1993, Kanski and Petty 1996, Woo and Wedderburn 1998).

JIA begins with systemic symptoms in 3 to $10 \%$ of patients. The peak age of onset is two years, and boys and girls are equally affected. High spiking fever and maculopapular rash are hallmarks of the disorder (Cassidy 1993, Woo and Wedderburn 1998). Arthritis may appear concurrent with the onset of systemic signs or even months later. Prominent visceral involvement (hepatosplenomegaly, lymphadenopathy and pericarditis) may accompany this subtype. Children affected are often seriously ill and drug management remains unsatisfactory. On the other hand, about a half of the cases are mild and may clear up spontaneously; the symptoms are treated with NSAIDs. If long-term treatment with high-dose corticosteroids is necessary the result may be undesirable side-effects such as osteoporosis, growth retardation and cataract formation. According to most studies the systemic disease subtype predominates among patients with secondary amyloidosis (Stoeber 1981). Uveitis is uncommon (Kanski and Petty 1996).

Enthesitis-related arthritis is believed to represent the childhood equivalent of the various forms of chronic spondyloarthropathies of adults. This is typically a disease of preteen and teenage boys, presenting as asymmetrical arthritis of the lower limbs and enthesitis. Most patients are positive for the HLA B27 allele and they frequently (in 5 to15\% in juvenile SPA and in $2 \%$ in Reiter's syndrome) have recurrent attacks of AAU. Sulfasalazine is the recommended treatment in addition to NSAIDs and local glucocorticoid injections. The functional outcome is usually good (Kanski and Petty 1996, Woo and Wedderburn, 1998).

Psoriatic arthritis frequently affects distal interphalangeal joints and patients may have polyarthritis involving large and small joints. In some cases the arthritis is highly erosive and difficult to manage. Chronic uveitis can occur in 10 to $15 \%$ of these patients. It is frequently chronic and asymptomatic and may prove refractory (Cassidy 1993, Kanski and Petty 1996, Woo and Wedderburn 1998). 


\subsubsection{Complications}

Severe JIA can cause growth retardation and even arrest of growth. Local inflammatory activity in a joint can result in accelerated growth of the epiphyses in the affected joint, e.g. in the knee, causing unequal leg length. Premature closing of the epiphyseal growth plates is the underlying reason for abnormal shortness of the digits (brachydactyly) and undue shortness of the lower jaw (micrognathia) (Woo and Wedderburn 1998). In a study from the former East Germany the overall frequency of growth retardation was $20 \%$, unevenly distributed over the main subgroups of JIA: $4 \%$ in oligoarthritis, $20 \%$ in polyarthritis, and as high as $46 \%$ in systemic onset arthritis (John and John 1984).

The long-lasting uncontrolled inflammation in JIA patients carries the risk of amyloidosis, a fatal complication of the disease. In amyloidosis inert insoluble fibrillar material with starchlike staining properties accumulates in different organs. The mechanism is unknown; hereditary or other factors may be involved, since only a minority of patients develop the disorder and its geographical distribution is uneven. Typically, amyloidosis is suspected when proteinuria appears. The diagnosis is frequently confirmed by biopsy (e.g. from subcutaneous fat or gingiva) (Klemi et al 1987). In Finland, the rate of amyloidosis in one hospital based study was $3 \%$ after a mean disease duration of 25 years (Ylijoki 1998). There is evidence that the incidence of amyloidosis in JIA is declining (Savolainen and Isomäki 1993, Savolainen and Ylijoki 1995).

Osteopenia in JIA is associated with inflammatory activity, immobility or loss of function, and glucocorticoid therapy. Body size, physical activity and calcium intake are significant positive determinants of bone mineral density in JIA patients in the same manner as in healthy children (Kotaniemi 1997).

Visual impairment in JIA is a consequence of chronic silent uveitis. This issue will be discussed in detail in a later section. 


\subsection{Uveitis}

Uveitis is a general term used for inflammation of the uveal tract (composed of iris, corpus ciliare and chorioidea i.e. the middle coat of the eye) due to any cause. It covers a large group of diverse diseases, which affect not only the uvea but also the retina and vitreous humor (Nussenblatt et al 1996).

\subsubsection{Anatomical criteria for uveitis}

The International Uveitis Study Group (IUSG, Bloch-Michel and Nussenblatt 1987) recommends classification of uveitis according to anatomical location as follows:

Anterior uveitis affects the iris and ciliary body as far back as the posterior limit of the pars plicata and it includes iritis, cyclitis and iridocyclitis.

Intermediate uveitis affects the pars plana ciliaris and peripheral retina. The terms formerly used are pars planitis, posterior cyclitis, hyalitis, basal retinochoroiditis, peripheral exudative retinitis and peripheral uveitis.

Posterior uveitis involves areas behind the posterior hyaloid membrane of the vitreous base. It can be focal, multifocal or diffuse. It includes choroiditis, chorioretinitis, retinochoroiditis and neurouveitis.

Panuveitis is a generalised inflammation of all three parts of the uvea.

Anterior uveitis is the most common form of the disorder, comprising 50 to $60 \%$ of cases (frequently associated with HLA B27) (Saari 1984), followed by posterior uveitis in 20 to $30 \%$, panuveitis in 10 to $20 \%$ and intermediate uveitis in about $10 \%$ of cases classified by location of the eye inflammation (Smit et al 1993, McCannel et al 1996, Rodriguez et al 1996).

The onset of uveitis may be sudden or insidious, and the duration short ( $<3$ months) or long (chronic) ( $\geq 3$ months). Its activity can be severe, mild or absent, the pattern of the disease single or repeated episodes, and uveitis can be unilateral or bilateral. It is classified as 
exogenous when it is caused directly by some infective agent, or endogenous when it occurs de novo without any obvious inciting agent (Forrester 1991). Endogenous uveitis has strong indirect links with infective agents implicated in its pathogenesis via several mechanisms, and the distinction between exogenous and endogenous uveitis has become blurred (Forrester 1991). The pattern of uveitis can be granulomatous, with large cells and 'mutton-fat keratic precipitates' (e.g. in sarcoidosis) and non-granulomatous, with small to medium-sized cells in the anterior chamber and on the corneal endothelium (e.g. in JIA).

\subsubsection{Etiological classification}

Classification of uveitis by etiology includes infectious, non-infectious and idiopathic uveitis. The etiology of the condition varies in different populations and areas (Rosenbaum and Cousins 1982, O'Brien et al 1994, Rodriguez et al 1996). The causative agents have changed over time: e.g. Treponema pallidum and Mycobacterium tuberculosis were regarded as the most frequent etiological factors in uveitis surveys before the 1950's, but at present these are rare etiological agents in immunocompetent patients in developed countries. Meanwhile new diseases have emerged, e.g. acquired immunodeficiency syndrome (Henderly et al 1987).

Infectious uveitis (if not associated with trauma) is caused by various pathogens: bacteria, viruses, fungi, parasitic worms and protozoa (Henderly et al 1987, Nussenblatt et al 1996). Toxoplasmic retinochoroiditis is the most common posterior uveitis in many countries. It is caused by the intracellular protozoan Toxoplasma gondii, and the vast majority of intraocular toxoplasmosis cases are congenital. The diagnosis is commonly made on grounds of the clinical picture. Uveitis and different types of retinitis caused by herpes-class viruses are becoming more common, together with cytomegalovirus retinitis in immunocompromised patients.

Non-infectious uveitis is a particularly heterogeneous group of uveitis entities including systemic immunological disease-associated chronic uveitis as well as those characterised by a specific clinical picture. This group consists of systemic diseases such as HLA B27-associated spondyloarthropathies, sarcoidosis and JIA. Specific uveitis entities include e.g. Fuchs heterochromic iridocyclitis or Posner-Schlossman syndrome or white-dot syndromes (O'Connor 1984, Rothova et al 1987, Rosenbaum 1989). 
Uveitis is designated idiopathic if no causative agent or any association with systemic diseases can be identified or if it cannot be categorised as a specific uveitis entity; in 25 to $50 \%$ of patients uveitis remains undetermined (Schlaegel 1958, Rothova et al 1987, Rosenbaum 1989, 1990, Rothova et al 1992, Rodriguez et al 1994).

\subsubsection{Occurrence}

The annual incidence of uveitis in Western societies is about 10-20/100 000 and there is little variation among figures reported from different countries (Miettinen 1977, Rothova et al 1996, Mercanti et al 2001). Recently, the average incidence of uveitis in north-eastern Italy was reported to be as low as 11.4/ 100000 (Mercanti et al 2001). The incidence of uveitis was highest among patients in the age group 25 to 44 years. The respective reported prevalences of uveitis reported in France and in south-western Finland were 38/100 000 and 23/100 000 (Vadot et al 1984, Päivönsalo-Hietanen et al 1997).

According to groups under Rothova and Mercanti, anterior uveitis was the predominant clinical type $(55 \%$ and $58 \%)$, followed by panuveitis (20\% and $13 \%)$, posterior uveitis (17\% and $26 \%$ ) and intermediate uveitis (9\% and 3\%, respectively) (Rothova et al 1992, Mercanti et al 2001).

Uveitis in children occurs less frequently than in adults, accounting for about $10 \%$ of all uveitis cases (Miettinen 1977, Pivetti-Pezzi 1996, Rodriguez et al 1996). In a recent Finnish survey involving 1122 uveitis patients only 55 (4.9\%) were children paralleling an incidence of 4.3/ 100000 in south-western Finland (Päivönsalo-Hietanen et al 2000). Most of the children in the study in question had anterior uveitis $(91 \%)$.

\subsubsection{Treatment}

The treatment of uveitis has three main goals: to prevent vision-threatening complications, to relieve the patient's complaints and, when feasible, to treat the underlying disease.

The mainstay of treatment of non-infectious uveitis is local therapy with corticosteroids and mydriatics. In refractory cases systemic steroids and other immunosuppressive drugs (cyclosporine, methotrexate and azathioprine, sometimes even chlorambucil or cyclophosphamide) are used (Nussenblatt et al 1991, Shah et al 1992, Kanski 1999, Jabs et al 2000). Very recently, Reiff and colleagues reported promising results of tumor necrosis factor $\alpha$ inhibition-treatment in cases with refractory childhood uveitis (Reiff et al 2001). 


\subsubsection{Complications}

Chronic uveitis can lead to structural damage to ocular tissues. Longstanding intraocular inflammation such as seen in JIA can cause an accumulation of calcium at the level of Bowman's membrane in the cornea, usually confined to the interpalpebral zone, a condition called band keratopathy. The clouded cornea can be cleared by chelating agents or excimer laser, but the deposition of calcium tends to recur (Rao et al 1992).

Cataract develops in uveitic eyes from a number of causes. Severe inflammation in the anterior chamber as well as posterior synechiae between iris and lens can result in anterior subcapsular lens opacities. Prolonged corticosteroid use is a common reason for posterior subcapsular cataract, which may also be associated with inflammation of the posterior chamber. Cataract is especially frequent in JIA-associated uveitis, Fuchs heterochromic iridocyclitis and intermediate uveitis (Rao et al 1992). Modern ophthalmic surgery has improved the prognosis of patients with secondary cataract, but the advisability of implanting an intraocular lens in an uveitic eye is still controversial (Foster and Barret 1993, BenEzra and Cohen 2000).

Secondary glaucoma can develop with any type of chronic inflammation. Blockage of the aqueous outflow due to inflammation of the trabecular meshwork and/or peripheral anterior synechiae, and pupillary block due to posterior synechia and secondary angle closure are the most common causes of elevation of intraocular pressure in uveitic patients. Another important cause of ocular hypertension is corticosteroid therapy; 3 to $10 \%$ of patients react to topical corticosteroids by an elevation of the intraocular pressure generally after 4 to 6 weeks' treatment. The reason for this is not known. Patients receiving systemic corticosteroid therapy have a lower incidence of elevated intraocular pressure. The degree of pressure rise is probably related to the strength and frequency of the medication used. Glaucoma is common in Fuchs heterochromic iridocyclitis and JIA-associated uveitis.

Glaucoma in chronic uveitis is often resistant to medical therapy. Cryo- or laser-surgery of the ciliary body or filtration surgery, especially the use of aqueous drainage devices, have improved the prognosis of this devastating complication of chronic uveitis (Rao et al 1992, Välimäki et al 1997). 
Cystoid macular edema (CME) is a major cause of visual impairment in patients with uveitis. Loss of foveal reflex and wet, glistening reflex in the foveal area are the first signs of CME, and this may progress to the cystoid pattern in a few weeks or months. Treatment of CME must be initiated early in view of the potential for permanent visual loss. Most often corticosteroids need to be employed (Rao et al 1992).

Severe uveitis can result in retinal detachment and finally in hypotony and phthisis bulbi. In these cases the prognosis is frequently poor, but surgical intervention may be of benefit in some cases, whereas retinal surgery in patients with longstanding uveitis is often unsuccessful (Rao et al 1992).

\subsubsection{Visual loss}

Uveitis is a significant cause of visual impairment. In most epidemiological studies concerning the underlying reasons for it, uveitis is seldom taken as a distinct entity. Accordingly, there is only little information on the incidence and the prevalence of blindness among the uveitis syndromes (Rothova et al 1996, Suttorp-Schulten and Rothova 1996). Based on studies from Western Europe and the United States it has been estimated that 5 to $15 \%$ of all cases of visual loss are caused by uveitis (ten Doesschate 1982, Nussenblatt et al 1996, Rothova et al 1996). According to Rothova and associates the most important cause of visual impairment in association with uveitis is $\mathrm{CME}$ and patients with panuveitis have the worst prognosis. Patients with JIA and sarcoidosis had the poorest visual prognosis in their cohort. Toxoplasmosis was the most frequent cause of visual loss in unilateral posterior uveitis (Rothova et al 1996).

\subsection{Uveitis in juvenile idiopathic arthritis}

\subsubsection{Historical review}

JIA has been recognised since the early 1800's, extra-articular manifestations of JIA being first described at the end of that century (Still 1897). However, the occurrence of iridocyclitis in patients with JIA was reported more than 10 years later (Ohm 1910). In the 1930's an association of arthritis, iridocyclitis, band keratopathy and cataract was noted in two children (Friedlander 1933) and later described in six JIA children (Blegvad 1941). It was soon 
understood that a definite disease subset exists in which both eyes and joints are affected, and this was subsequently confirmed in numerous additional reports (Vesterdal and Sury 1950, Franceschetti et al 1951, Smiley et al 1957, Ansell and Bywaters 1959, Schaller et al 1969, Calabro et al 1970, Schaller et al 1974, Chylack et al 1975, Chylack 1977, Kanski 1977, Rosenberg and Oen 1986, Rosenberg 1987).

\subsubsection{Occurrence of uveitis in juvenile idiopathic arthritis}

In different series the figures for the occurrence of uveitis vary greatly, as seen in Table 3. The frequency of the condition in different subtypes of JIA is discussed more thoroughly at a later point. 
Table 3. The occurrence of uveitis in juvenile idiopathic arthritis (JIA)

\begin{tabular}{lcccc}
\hline Authors & Country & Year & $\begin{array}{c}\text { Children with uveitis } \\
\text { / all children, } \mathrm{n}\end{array}$ & $\begin{array}{c}\text { Occurrence of uveitis \% } \\
\text { (95\% CI) }\end{array}$ \\
\hline Smiley & UK & 1965 & $29 / 350$ & $8.3(5.6$ to 11.7$)$ \\
Laaksonen & Finland & 1966 & $23 / 411$ & $5.6(3.6$ to 8.3$)$ \\
Spalter & USA & 1975 & $34 / 211$ & $16.1(11.2$ to 21.1$)$ \\
Chylack et al & USA & 1975 & $36 / 210$ & $17.1(12.0$ to 22.2$)$ \\
Cassidy et al & USA & 1977 & $38 / 368$ & $10.3(7.2$ to 13.4$)$ \\
Towner et al & USA & 1983 & $2 / 49$ & $4(0.5$ to 14.0$)$ \\
Kunnamo et al & Finland & 1986 & $6 / 29$ & $21(8.0$ to 39.7) \\
Kanski & UK & 1988 & $25 / 122$ & $20.5(13.3$ to 27.7$)$ \\
Andersson Gäre and & Sweden & 1995 & $11 / 124$ & $8.9(4.5$ to 15.3$)$ \\
Fasth & & & & $9.3(7.4$ to 11.6$)$ \\
Candell Chalom et al & USA & 1997 & $71 / 760$ & $13.8(7.3$ to 20.2) \\
Moe and Rygg & Norway & 1998 & $15 / 109$ & $23.0(16.7$ to 29.2) \\
Ylijoki & Finland & 1998 & $40 / 174$ & \\
\hline
\end{tabular}

Variations in the length of follow-up and the thoroughness with which the eyes were examined have quite obviously contributed to the discrepant estimates of the occurrence of uveitis. Most studies are from special pediatric or ophthalmologic centres and only a minority have been population-based (Kanski 1988, Andersson Gäre 1999). The lower frequency of uveitis in early reports was evidently partly due to the fact that not all children with JIA had been examined by an ophthalmologist (Laaksonen 1966). There may also be real differences between the incidences of uveitis detected in the United States and in Europe: e.g. 4 to $17 \%$ in the USA, compared to $20 \%$ in the United Kingdom and $21 \%$ and $23 \%$ in Finland (Chylack et al 1975, Cassidy et al 1977, Towner et al 1983, Kunnamo et al 1986, Kanski 1988, Candell Chalom et al 1997, Ylijoki 1998). Later studies give lower figures for northern Europe, e.g. 9\% and 15\% in south-western Sweden in two population-based series (Andersson Gäre and Fasth 1995) and $14 \%$ in a study from northern Norway (Moe and Rygg 1998). On the grounds of the above it would seem that uveitis in JIA patients may be less frequent in the USA than in most European societies. 


\subsubsection{Clinical picture of uveitis in juvenile idiopathic arthritis}

At the beginning of the last century the eye manifestations of JIA were commonly described as the 'ocular triad of Still's disease', comprising iritis, band keratopathy and cataract. Since then, numerous cases with JIA and eye lesions have been published, especially in the German literature, and it became an established fact that uveitis was more frequent in JIA than among the general child population (Blegvad 1941, Vesterdal and Sury 1950, Franceschetti 1951).

Formerly, the eyes were examined with loupe and ophthalmoscope, and not all patients were examined by an ophthalmologist with a slit-lamp microscope (Smiley et al 1957). For this reason, perhaps even most of the JIA children with mild asymptomatic uveitis were missed, and the more severe cases with band keratopathy and cataracts, frequently leading to visual loss, were preferentially diagnosed.

In any case, it was early understood that uveitis is in most cases insidious at onset and has a chronic, sometimes remitting course. In most cases both eyes are affected, either simultaneously or within a few months of each other (Kanski 1990, Dana et al 1997). It is uncommon that in initially unilateral uveitis the inflammation develops in the other eye more than a year from the onset of the process (Steward and Hill 1967, Smiley 1974, Kanski 1990). In a majority of cases, uveitis is nongranulomatous, with a faint flare and only a few cells in the anterior chamber, by no means easily detectable. Keratic precipitates are from small to medium in size, seen mainly in the inferior half of the corneal endothelium. In moderate or severe uveitis, cells can be seen in the anterior vitreous and the inflammation may also spread to the posterior parts of the eye, sometimes resulting in CME (Kanski 1990).

AAU with redness and pain tends to occur in older children, and formerly this was regarded as a transitory form between silent uveitis in children and the acute recurrent type of iritis of adult years (Vesterdal and Sury 1950). AAU is often found in connection with enthesitis-related arthritis in children positive for HLA B27, most of whom are boys at the age of 10 or more. They may later develop spondyloarthropathy, where AAU is a feature of the disease in up to $25 \%$ of patients in adulthood (Kanski 1990, Andersson Gäre 1999).

It has been reported that although the activities of joint and eye inflammation may parallel each other, they are in fact more commonly independent (Rosenberg and Oen 1986), and a recent 
study suggests that the presence of uveitis does not influence the long-term articular prognosis of oligoarthritis (Cimaz and Fink 1996). However, long-term follow-up studies of this aspect are so far lacking.

\subsubsection{Characteristics of uveitis patients in juvenile idiopathic arthritis}

\subsubsection{Risk of uveitis in subtypes of arthritis}

JIA was early divided according to onset type into three main subtypes: oligoarthritis (earlyonset: $<8$ years of age, and late-onset: $\geq 8$ years of age), polyarthritis (mostly RF-negative), and systemic onset arthritis. The risk of uveitis is greatest in patients with oligoarthritis, $20 \%$ and about 5\% in polyarthritis, while it is rarely detected in systemic-onset JIA (Cassidy 1993, Kanski and Petty 1996). Of patients with JIA-associated uveitis, 78 to $91 \%$ belong to the oligoarthritis group, 7 to $14 \%$ have polyarthritis and only 1 to $6 \%$ of these children have systemic-onset JIA (Kanski 1990, Rao et al 1992). RF-positive patients only seldom develop uveitis (Kanski 1990, Kanski and Petty 1996, Dana et al 1997).

\subsubsection{Risk of uveitis according to gender}

JIA is more frequent in girls than in boys (sex ratio 3:2), but, independent of this, girls carry a higher risk of uveitis than do boys (Kanski 1990, Dana et al 1997). The proportion of girls among JIA patients varies from 71 to $97 \%$, and the male/female ratio in JIA patients with uveitis is about 1:5 (Ohno et al 1977, Kanski and Shun-Shin 1984, Rosenberg and Oen 1986, Wolf et al 1987, Kanski 1989, 1990, Candell Chalom et al 1997). In a recent study, moreover, uveitis was found to begin four years earlier in girls than in boys and the duration of active disease was longer in girls (Dana et al 1997). Similarly, chronic anterior uveitis in children without arthritis is more common in girls; no explanation for this can as yet be given (Perkins 1966, Ohno et al 1977, Päivönsalo-Hietanen et al 1997).

\subsubsection{Onset of uveitis in relation to age of child and onset of arthritis.}

In the majority of children the joint symptoms precede the detection of uveitis and in only $6 \%$ of cases does uveitis develop first, although higher figures have also been reported (Wolf et al 1987, Kanski 1990, Dana et al 1997). Uveitis is usually detected during the first seven years of 
arthritis, but the interval may even be longer than 20 years. Recently, in a large cohort consisting of 760 JIA patients in the United States $90 \%$ of uveitis cases were found within the first 4 years of JIA (Candell Chalom et al 1997). The mean interval from the diagnosis of JIA to the onset of uveitis in this series was 21 months. According to Kanski the mean age at diagnosis of uveitis is 6 years (range 1 to 35 years) (Kanski 1990), whereas among 43 uveitis children with JIA in Boston the mean known age at the onset of uveitis has been found to be as high as 13 years (Dana et al 1997). If uveitis is diagnosed first, it is often severe, because the diagnosis of asymptomatic uveitis is obviously delayed (Kanski 1990).

In HLA B27-positive boys with late-onset oligoarthritis the possibility of AAU is evident and it can precede joint symptoms by months or even years (Giannini et al 1991).

\subsubsection{Genetic factors in juvenile idiopathic arthritis with uveitis}

Histocompatibility allele profiles have been studied in uveitis associated with early-onset oligoarthritis. In two American series, the HLA allele DRB1*1104 (a split of HLA DR 5) was seen to occur significantly more frequently in patients with chronic uveitis compared to those not suffering from the disorder (Malagon et al 1992, Melin-Aldana et al 1992). No corresponding difference emerged in a patient series collected in Central Europe (Haas et al 1994). In all three series, the frequency of the allele DRB $1 * 01$ was reduced. No data on HLA allele distributions in chronic uveitis associated with other forms of JIA have been published, probably due to the small number of available cases. The association of ANA with early-onset oligoarthritis and uveitis is a known fact, as is the HLA B27 positivity in boys with an older age of onset of their arthritis who have AAU and are negative for ANA and RF.

\subsubsection{Treatment of uveitis in juvenile idiopathic arthritis}

The goal of treatment is to cure the uveitis as soon as possible from the very beginning of the inflammation in order to save visual acuity and to prevent severe complications of chronic uveitis (cataract, glaucoma, CME and band keratopathy). JIA patients with uveitis should be referred to an experienced ophthalmologist for treatment and follow-up. Treatment of arthritis and uveitis should be undertaken in close co-operation with pediatric rheumatologists familiar with the use of immunosuppressive and immunomodulatory medications (Dunn 1996). Further 
reduction of irreversible visual loss from uveitis is achieved only by early diagnosis and prompt treatment of the disorder (Dollfus 1998, Nguyen and Foster 1998).

\subsubsection{Local treatment}

The mainstay of treatment in uveitis is local therapy with corticosteroids and mydriatics. Most cases can be controlled by topical corticosteroid treatment. Topical use of NSAIDs may be added to the regimen (Kanski 1990, Dunn 1996, Dollfus 1998, Nguyen and Foster 1998). Periocular corticosteroid injections are sometimes used in refractory cases. Frequently the treatment has to be continued for several months, even for years. The frequency of treatment is slowly tapered to a level, which keeps the eye inflammation under control. Upon cessation of treatment the eyes have to be re-examined within the next few days or weeks to detect possible recurrence of uveitis.

Short-acting mydriatics, e.g. tropicamid or cyclopentolate, are commonly used to prevent the formation of posterior synechiae between iris and lens. Long-acting mydriatic drops such as atropine may cause adhesions in the chamber angle and are recommended only in severe cases. Constant mydriasis may impair the development of normal central visual acuity and result in a form of vision deprivation called amblyopia (Kanski 1990)

\subsubsection{Systemic treatment}

If uveitis is severe or prolonged, systemic steroids are frequently used, at onset with larger doses and subsequently tapering to as low a level as necessary to stabilise the situation. Most JIA patients have NSAIDs in their treatment, usually naproxen. In about $30 \%$ of patients with JIA-associated uveitis the inflammation cannot be controlled by anti-inflammatory agents only, and initiation of low-dose, once-a-week methotrexate therapy is recommended. The dosage of methotrexate can be increased even to $17.5-20.0 \mathrm{mg}$ per week to control the uveitis. There is some evidence that this drug has both anti-inflammatory and immunosuppressive effects, while folic acid can prevent adverse effects (Nguyen and Foster 1998). If methotrexate is not well tolerated or is ineffective, other immunomodulatory drugs can replace it or be used in combination with it: azathioprine, low-dose cyclosporine, or even chlorambucil or cyclophosphamide (Hemady et al 1992, Schlote et al 1996, Vitale et al 1996, Savolainen et al 1997, Weiss et al 1998, Savolainen 1999). In some refractory chronic uveitis patients, treatment 
with intravenous immunoglobulin has been tried, but there is no documentation of its effect in childhood uveitis (Rosenbaum et al 1999).

\subsubsection{Screening for uveitis in juvenile idiopathic arthritis}

Ophthalmologic examination of patients with JIA was highly recommended as far back as 1957 (Smiley et al 1957). Subsequently Kanski published several papers on JIA-associated uveitis and his screening program is widely accepted. It is presented in Table 4 (Kanski 1989).

Table 4. Screening program for uveitis in juvenile idiopathic arthritis

\begin{tabular}{lcc}
\hline Onset type of JIA & Risk of uveitis & Interval between eye examinations \\
\hline Systemic & $(+)$ & 12 months \\
Polyarticular & + & 6 months \\
Polyarticular, ANA-positive & ++ & 6 months \\
Pauciarticular & +++ & $3-4$ months \\
Pauciarticular, ANA-positive & ++++ & $2-3$ months \\
\hline
\end{tabular}

It is reasonable to monitor all JIA patients for at least seven years from the onset of arthritis. Uveitis will commonly appear within 12 months, and in $90 \%$ of cases during the first 4 to 5 years of arthritis (Kanski 1990, Dollfus 1998). Similar guidelines for ophthalmologic examinations in children with JIA have also been recommended elsewhere (Yancey et al 1993, Boone et al 1998).

\subsubsection{Prognosis of uveitis in juvenile idiopathic arthritis}

The prognosis of JIA-associated uveitis has continuously improved (Sherry et al 1991, Cabral et al 1994, Dana et al 1997). In the first reports on uveitis in JIA the complication rate was very high, partly owing to a delay in the diagnosis of uveitis. It was commonly thought that most patients with band keratopathy would eventually become blind. In 1957 Smiley and colleagues reported that 10 out of 183 children with JIA had uveitis, and band keratopathy was found in five of them, cataract in three and secondary glaucoma in one child. Visual acuity was 
preserved normal in five cases and uveitis was ongoing in five. One child was referred because of longstanding uveitis: cataract and blindness were recorded 2.5 years before the onset of arthritis (Smiley et al 1957). In the study of 51 JIA patients by Wolf and associates, $22 \%$ of 89 eyes with uveitis had visual loss to 20/200 or worse, and complications were common: cataract in $46 \%$, band keratopathy in $30 \%$, and glaucoma in $27 \%$ of the eyes. The degree of inflammation found on initial ocular examination correlated with the severity of visual loss and complications (Wolf et al 1987).

According to Kanski, 25\% of JIA patients with uveitis have a good prognosis: patients either do not need medication or do well with only topical corticosteroids. Half of his 103 patients had moderate to severe uveitis with good response to treatment, but needed long-term therapy. A poor prognosis with complicating cataract and glaucoma was found in $25 \%$ of children (Kanski 1988).

A report published a decade ago compared the severity of chronic uveitis in children with juvenile oligoarthritis in Seattle in 1975 and in 1989. The prevalence of eye diseases declined from $45 \%$ to $13 \%$ and the proportion of patients with severe visual loss diminished from $21 \%$ to zero (Sherry et al 1991). More effective treatment and early detection of uveitis obviously played some role, but there may also have been differences in the selection of patients.

Cabral and associates summarised the prognostic data from previous studies and concluded that the risk of developing uveitis five years after the onset of JIA was small (Cabral et al 1994). The complication rate in their own series was $31 \%$. On the other hand, normal vision was saved in the majority of their patients with JIA/juvenile psoriatic arthritis and uveitis.

One recent study of JIA-associated uveitis has evaluated visual outcome prognosticators retrospectively in a series of 43 patients (Dana et al 1997). Uveitis was chronic in 93\%, and $97 \%$ had iridocyclitis. Cataract surgery was performed in $44 \%$ of cases, and $37 \%$ underwent vitrectomy. Male sex, shorter duration of uveitis, older age at disease onset, and a shorter delay in presentation to an experienced ophthalmologist were associated with improvement in visual acuity.

In a Finnish prospective 15-year follow-up of 174 children with JIA, four (2\%) had decreased visual acuity $(<20 / 70)$; two of them had had uveitis, the other two cataract (Ylijoki 1998). 
Better prognosis of uveitis may be a consequence of routine screening of JIA patients for its detection and advances in the medical and surgical treatment of both arthritis and uveitis (Dana et al 1997). As shown in the above-mentioned studies, the complication rate today is lower than earlier and the visual prognosis has improved. The frequency of band keratopathy has diminished, and due to modern surgical techniques it is possible to restore good visual acuity after cataract and glaucoma operations. Formerly secondary glaucoma due to chronic uveitis was an important cause of visual loss, its response to medical treatment often being poor. However, the known complications of prolonged use of corticosteroids: ocular hypertension and posterior capsular cataract, are frequently seen in patients with chronic uveitis, and in some patients the development of CME causes permanent visual impairment despite vigorous treatment of uveitis (Nguyen and Foster 1998). 


\section{AIMS OF THE PRESENT STUDY}

The impulse to undertake the present thesis came from observations made in the context of practical work with patients suffering JIA-associated uveitis (I). It became clear that systematic efforts to increase knowledge of the occurrence, characteristics and prognosis of this condition improves its treatment and the prognosis of patients.

There are only few population-based studies providing information on the occurrence of uveitis in patients with JIA, and none of these has dealt specifically with eye problems. A populationbased patient series had already been collected in Finland (Kaipiainen-Seppänen and Savolainen 1996) and the patients were now evaluated from the ophthalmological point of view (II).

A number of studies have dealt with the HLA associations of JIA-associated uveitis. There are, however, very few sibling series on JIA and no special attention has been paid in these to uveitis. One sibling series had been collected at the Rheumatism Foundation Hospital in Heinola (Savolainen et al 2000) and the occurrence and characteristics of uveitis in these sibling pairs is described in study III.

The majority of studies on JIA-associated uveitis are retrospective and come from special ophthalmologic or pediatric centres. A prospective study of the occurrence and characteristics of uveitis among patients with recently diagnosed JIA at the Rheumatism Foundation Hospital was carried out in close co-operation with an ophthalmologist and pediatric rheumatologists (IV).

It is commonly believed that arthritis in JIA patients is usually mild and has a good prognosis, but there is very little solid evidence substantiating this view. The activity of arthritis in RFnegative JIA patients with oligoarthritis or polyarthritis in study IV was compared between cases with and without uveitis (V).

There is very little information available on the relative importance of different arthritides and comparable conditions as a cause of visual loss. The Finnish Register of Visual Impairment provided a basis to approach this issue and a study was carried out along these lines (VI). 


\section{PATIENTS AND METHODS}

\subsection{Utilization of the Finnish registers}

The Finnish health care system is mainly public. In addition to the nation-wide sickness insurance scheme, several other population-based registers exist, e.g. The Finnish Register of Visually Impaired. These sources provide a good basis for epidemiological studies.

\subsubsection{The Finnish sickness insurance scheme}

Since 1966 The Finnish Sickness Insurance Act has provided for the prescription of drugs free of charge for certain chronic conditions, including chronic inflammatory rheumatic diseases. Following a number of amendments, only $75 \%$ of costs are nowadays reimbursed. The Finnish national sickness insurance scheme covers the entire population. Eligibility requires a comprehensive medical certificate written by the attending physician and approved by an expert adviser on behalf of the sickness insurance scheme.

The epidemiological section of this thesis (II) involved the 114 JIA children (the term JRA was used in the original communication), in whom the diagnosis had been made in 1980, 1985 and 1990 in the districts of five of the 21 central hospitals in Finland (Keski-Suomi, Tampere, Päijät-Häme, Kymenlaakso, Kuopio) (Kaipiainen-Seppänen and Savolainen 1996).

The study area (Figure 1) covered about 1300000 inhabitants, i.e. one-fourth of the population of Finland, including a population base of about 270000 children under 16 years. The patients in this study were entitled to specially reimbursed medication for JIA. A patient was defined as an incident case if his/her age at the time of diagnosis was under 16 years and if he/she met the ARA criteria (Brewer et al 1977). 


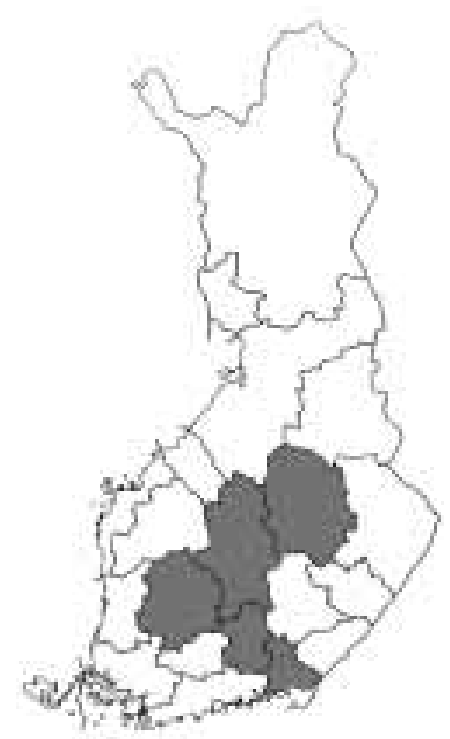

Figure 1. The study area of the population-based JIA series

In this retrospective study the clinical data on the course of arthritis and associated uveitis were collected from drug reimbursement certificates and hospital records covering the period up to autumn 1997. The occurrence and characteristics of uveitis were determined.

\subsubsection{The Finnish Register of Visual Impairment}

The Finnish Register of Visual Impairment was founded in 1983. Its function is regulated by law and it is technically maintained by the Finnish Federation of Visually Impaired under the supervision of a governmental office (National Research and Development Centre for Welfare and Health). Specialists in ophthalmology (about 420 in a population of 5.1 million at the end of 1997) and the ophthalmologic hospital units are obliged to give notification of patients in whom the corrected visual acuity is permanently less than 20/60 in the better eye or if the patient for some other reason (e.g. visual field defects) is regarded as comparable in respect of the above visual impairment. The notification form provides information on the patient's personal details, diagnoses and severity of visual impairment (visual acuity and visual field). 
This register provided a basis for a study of the importance of different uveitis entities as a cause of visual handicap (VI); special emphasis was paid to arthritides and comparable conditions. The coverage of the register is not complete, but during the last few years the proportion of different diagnostic categories and the age distribution of cases have been quite stable. At the end of 1996, the register covered 11022 living persons, including 296 subjects (2.9\%) diagnosed as having uveitis. The most common causes of visual impairment in 1996 were senile macular degeneration 35\%, hereditary retinal degeneration and diabetic retinopathy $10 \%$ each, glaucoma and other diseases of the optic pathway $9 \%$, and congenital developmental defects $6 \%$.

On the basis of the Finnish Register of Visual Impairment a total of 296 uveitis patients were found and data concerning these patients were collected from hospital records. The information obtained was frequently incomplete on patients blinded a long time ago. For this reason only those 174 patients who had been handicapped during 1980-1996 were included in the present study. The demographics of the patients, the clinical course of uveitis, and possible associations with systemic diseases were evaluated (VI).

\subsection{Patients with juvenile idiopathic arthritis from the Rheumatism Foundation Hospital}

Finland is divided into five university hospital regions, each covering about one million inhabitants, and further into 21 central hospital districts. Patients come to central hospitals from primary care, i.e. from health centres, which are responsible for health care and health checkups of residents in their districts. Patients are required to attend their own local health facilities except in emergencies. In addition to this tax-financed system there are private physicians who can refer patients to hospitals of all levels. Very few private clinics exist in Finland; some of these are also partially financed from public resources.

The Rheumatism Foundation Hospital is a semi-private clinic, which receives patients from university hospitals and other central hospitals, and directly from primary care, especially if patients live in the region surrounding the Hospital. The Hospital provides in- and outpatient care in conservative rheumatology, orthopedics and rehabilitation for adults and children. Of JIA patients only the mildest cases remain in the care of central hospitals, others being referred 
further to university clinics or to the Rheumatism Foundation Hospital. It has been estimated, on the basis of an incidence study in Finland (Kaipiainen-Seppänen and Savolainen 1996) and the patient register of the Rheumatism Foundation Hospital, that about two-thirds of JIA patients are seen at the Hospital at some time, in many cases once or twice, while severe cases are constantly monitored there (II).

A series of siblings affected with JIA was collected at the Rheumatism Foundation Hospital over a period of 15 years. Patients (when appropriate) and their parents were systemically asked about their family history of rheumatic diseases. Altogether 37 families with two or three affected siblings were identified; there were 80 children (49 sib pairs) with a diagnosis of JIA according to the Durban criteria (Petty and Southwood 1998). The total number of JIA patients among whom the familial cases were found was estimated to be 2000 (Savolainen et al 2000). Except for five patients, all the siblings had been treated at the Rheumatism Foundation Hospital. All were examined by an ophthalmologist at the Hospital or at central hospitals 2 to 4 times a year for detection of insidious uveitis. The occurrence and characteristics of uveitis were assessed in this series (III).

At the Rheumatism Foundation Hospital a total of 426 children with recently diagnosed JIA during the period 1989-1996 were sent for ophthalmologic examination for possible insidious uveitis. The occurrence and characteristics of uveitis were assessed prospectively in this patient series. During the follow-up an ophthalmologic examination was carried out 2 to 4 times a year, more often in cases with uveitis (IV).

In the above patient series uveitis was found in 104 out of 426 cases with JIA. The activity of arthritis in JIA patients with RF-negative oligoarthritis or polyarthritis without uveitis (276 patients) and with it (96 patients) were compared (V). Remission of JIA was stated recorded, if no tender or inflamed joints were found and the patients' erythrocyte sedimentation rate (ESR, $<10 \mathrm{~mm} / \mathrm{h}$ ) and/or C-reactive protein (CRP, <10mg/l) were normal. Additionally, patients had had no medication or other treatment for arthritis during the last six months (remission without drugs). 


\subsubsection{Diagnosis of juvenile idiopathic arthritis and follow-up of patients}

Pediatric rheumatologists confirmed the diagnosis of JIA in all patients according to approved main criteria (Brewer et al 1977, Wood 1978, Petty and Southwood 1998). The subtype of arthritis was defined after six months' duration of JIA. The characteristics and course of the disease were evaluated during the follow-up. ANA and RF were determined in almost all cases, HLA B27 less frequently. The clinical status of patients with active JIA was followed by pediatricians after regular intervals, usually 2 to 6 times a year.

\subsubsection{Ophthalmologic examination, treatment and follow-up of uveitis}

All patients with suspected or diagnosed JIA were sent for ophthalmologic examination to detect insidious uveitis as soon as possible after the onset of arthritis, and 2 to 4 times yearly thereafter. The examination included determination of the best corrected visual acuity, careful biomicroscopy of the anterior segment of the eye and evaluation of cells and aqueous flare. After dilatation of the pupil (by tropicamide or/and cyclopentolate and phenylephrin when needed) examination of the anterior vitreous body was performed under slit lamp and the fundus of the eye was studied with a 90 dioptre lens. Ocular pressure was measured when feasible. Uveitis was classified according to the recommendations of the IUSG (Bloch-Michell and Nussenblatt 1987). Grading of anterior chamber flare and cells was done with modification of the recommendations of Rao and Foster (1992) and Nussenblatt and group (1996). The data are presented in Table 5 .

Table 5. Grading of anterior chamber flare and cells in uveitis in JIA

Anterior chamber flare (wide beam and narrow slit)

Grade Description

$0 \quad$ None

$1+\quad$ Faint flare (barely detectable)

2+ Moderate flare (iris and lens clearly seen)

3+ Marked flare (iris and lens hazy)

4+ Intense flare (coagulated aqueous humour with fibrin)
Anterior chamber cells per field

Grade Description

0

None

1+ 3-10 cells

$2+\quad 10-20$ cells

$3+$

20-50 cells

$4+$

$50+$ cells 
Because the majority of our patients were young and biomicroscopic examination was sometimes technically difficult, wide beam and narrow slit were commonly used (IV and V). The patient was assessed as having anterior uveitis when three or more cells in the anterior chamber and/or precipitates on the endothelium were found in biomicroscopy. Aqueous flare alone was not taken as a sign of active inflammation. Inflammation in the vitreous body was evaluated according to the recommendations of Nussenblatt and colleagues (1996). The characteristics and course of uveitis were recorded and complications (cataract, glaucoma, CME and band keratopathy) were carefully registered. CME was evaluated clinically (fluorescein angiography was not available) (Rao et al 1992, Nussenblatt et al 1996). Treatment of uveitis was initiated promptly after the diagnosis by local therapy, which was reinforced in refractory cases with systemic therapy in close co-operation with pediatric rheumatologists (IV, V) or rheumatologists (I).

\subsection{Statistical methods}

The results in the studies discussed here are expressed as mean, standard deviation (SD), range, and 95 per cent confidence intervals $(95 \% \mathrm{CI})$. Statistical significance was evaluated by T-test, Fisher's exact test, Mann-Whitney test and Chi-square test (II - V). The normality of variables was evaluated by Kolmogorov-Smirnov statistics, with Lilliefors significance or Shapiro-Wilk statistics (II-VI). Kaplan-Meier curves were used to illustrate information on the cumulative proportions of uveitis and the difference between groups tested by Log-rank test (IV). Prognostic factors predicting uveitis were analysed using univariate and multivariate proportional hazard regression models (Cox's regression models) (IV). 


\section{RESULTS}

\subsection{Occurrence of uveitis in juvenile idiopathic arthritis (I, II, III, IV)}

\subsubsection{Late-onset uveitis in juvenile-type chronic polyarthritis - a case report (I)}

A female with seronegative polyarthritis since early adulthood developed silent chronic uveitis 15 years after the onset of arthritis. The polyarthritis was diagnosed after the 16th birthday, but re-examination of the patient records revealed an erosive finger joint visible in X-rays at the age of 14. The patient was ANA-positive and carried the HLA B27 antigen. Arthritis was refractory to conventional anti-rheumatic medication and severe uveitis did not respond to either topical corticosteroid treatment or oral corticosteroid plus cyclosporine. Finally, combination therapy with oral corticosteroids, cyclosporin A and methotrexate calmed down the sight-threatening uveitis and aggressive polyarthritis within two months. The collaboration of ophthalmologist and rheumatologists was important in treating this patient in respect of determining the optimal management.

\subsubsection{Population-based occurrence of uveitis in juvenile idiopathic arthritis (II)}

Uveitis was found in 18 out of the 114 JIA patients (16\%). A total of $70 \%$ of these 114 were female, in $75 \%$ the onset type of JIA was oligoarticular and $43 \%$ of the patients were ANApositive. Only four cases were RF-positive, while systemic onset JIA was diagnosed in seven. The mean age at the diagnosis of JIA was 7.4 years (range 0.8-15.8 years). HLA B27 was positive in 24 out of 66 HLA-typed patients. The mean follow-up period was 7.5 years (range 0.5-17 years). 
Table 6. Main characteristics of 18 juvenile idiopathic arthritis patients with uveitis in a population based-group of 114 children.

Characteristic

Type of uveitis

\begin{tabular}{|c|c|c|c|c|}
\hline & & & & \\
\hline & Chronic & $\begin{array}{l}\text { Healed } \\
\text { chronic }\end{array}$ & Episodic & $\begin{array}{l}\text { Acute with } \\
\text { symptoms }\end{array}$ \\
\hline Male/Female, n & $3 / 3$ & $1 / 2$ & $0 / 7$ & $2 / 0$ \\
\hline $\begin{array}{l}\text { Oligoarthritis/polyarthritis cases at } \\
\text { onset of arthritis, } \mathrm{n}\end{array}$ & $4 / 2$ & $2 / 1$ & $5 / 2$ & $2 / 0$ \\
\hline $\begin{array}{l}\text { Age at onset of arthritis, mean } \\
\text { (range), yrs }\end{array}$ & $\begin{array}{c}5.2 \\
(1.5 \text { to } 15.8)\end{array}$ & $\begin{array}{c}5.0 \\
(4.0 \text { to } 5.9)\end{array}$ & $\begin{array}{c}7.1 \\
(1.6 \text { to } 14.3)\end{array}$ & $\begin{array}{c}13.4 \\
(13.1 \text { to } 13.6)\end{array}$ \\
\hline $\begin{array}{l}\text { \#Interval to uveitis, mean (range), } \\
\text { yrs }\end{array}$ & $\begin{array}{l}1.7 \\
(0 \text { to } 8.2)\end{array}$ & $\begin{array}{c}3.4 \\
(0 \text { to } 5.6)\end{array}$ & $\begin{array}{c}4.7 \\
\text { (0 to } 11.7)\end{array}$ & $\begin{array}{c}-0.5 \\
(-0.6 \text { to }-0.4)\end{array}$ \\
\hline Uni-/bilateral uveitis cases, $\mathrm{n}$ & $2 / 4$ & $0 / 3$ & $6 / 1$ & $2 / 0$ \\
\hline ANA-positive/negative children, $\mathrm{n}$ & $3 / 3$ & $2 / 1$ & $4 / 2 *$ & $0 / 2$ \\
\hline $\begin{array}{l}\text { HLA B27-positive/negative } \\
\text { children }^{\S}, \mathrm{n}\end{array}$ & $1 / 2$ & $0 / 3$ & $2 / 0$ & $2 / 0$ \\
\hline
\end{tabular}

*One patient not tested; ${ }^{\S}$ eight patients not tested

\#Interval from arthritis to uveitis denotes interval between the onset of arthritis and the onset of uveitis; a negative value implies that uveitis was detected prior to arthritis.

As seen in Table 6, uveitis was found in 18 patients (16\%). The male/female ratio was $1: 2 ; 13$ children had oligoarthritis (mean age 5.7 years at the diagnosis of JIA) and five had polyarthritis (mean age 9.7 years at the diagnosis of JIA). The diagnosis of JIA was made at a mean age of 6.8 years (range 1.3-15.8 years) in the case of those 18 with uveitis. The uveitis diagnosis was made at a mean age of 9.7 years ( 8.8 years in oligoarthritis). The onset of uveitis was asymptomatic in most patients (15/18) and bilateral in eight; only two HLA B27-positive boys with late-onset oligoarthritis had acute symptomatic uveitis of short duration, and one girl had marginal corneal ulceration and mild uveitis at the onset of her RF-positive polyarthritis.

In six patients uveitis ran a chronic course and led to complications (cataract, glaucoma or $\mathrm{CME}$ ) in three cases; in all these patients uveitis had preceded the onset of arthritis. The overall 
visual prognosis was nonetheless good; in only one patient did visual acuity in one eye remain as low as $20 / 400$.

\subsubsection{Occurrence of uveitis in sibling pairs with juvenile idiopathic arthritis (III)}

A total of 80 JIA children belonging to 37 families with two or three affected siblings (49 sib pairs) were found at the Rheumatism Foundation Hospital during 15 years. Uveitis was diagnosed in 21 of the patients (26\%). Three pairs were concordant for the presence of uveitis. The expected number was 3.4.

In this series of JIA patients with uveitis both genders were similarly affected. Oligoarthritis was the most frequent type of JIA, and ANA positivity was common. Patients with uveitis were somewhat younger at the onset of JIA than those without. Patients with uveitis tended to be more frequently positive for HLA B27 compared to those without; all siblings concordant for uveitis carried this allele. 
Table 7. Main characteristics of the 21 JIA patients with uveitis in the sibling study

\begin{tabular}{|c|c|c|c|c|c|c|c|c|}
\hline Type of uveitis & Sex & $\begin{array}{l}\text { Onset } \\
\text { type of } \\
\text { JIA }\end{array}$ & $\begin{array}{c}\text { Course } \\
\text { type of } \\
\text { JIA }\end{array}$ & $\begin{array}{c}\text { Age at } \\
\text { diagnosis } \\
\text { of JIA, } \\
\text { yrs }\end{array}$ & $\begin{array}{c}\text { Interval } \\
\text { to } \\
\text { uveitis*, } \\
\text { yrs }\end{array}$ & $\begin{array}{c}\text { Eye } \\
\text { afflicted }\end{array}$ & ANA & $\begin{array}{l}\text { HLA } \\
\text { B27 }\end{array}$ \\
\hline
\end{tabular}

Three sibling pairs,

concordant for uveitis:

$\begin{array}{lccccccc}\text { healed chronic } & \text { F } & \text { oligo } & \text { oligo } & 6.0 & 0.2 & \text { left } & + \\ \text { chronic } & \text { F } & \text { oligo } & \text { oligo } & 2.3 & 3.1 & \text { left } & - \\ \text { healed chronic } & \text { M } & \text { oligo } & \text { oligo } & 2.8 & 5.0 & \text { both } & - \\ \text { chronic } & \text { F } & \text { oligo } & \text { oligo } & 4.0 & 1.3 & \text { left } & + \\ \text { healed chronic } & \text { F } & \text { oligo } & \text { oligo } & 1.3 & 0.2 & \text { both } & + \\ \text { chronic } & \text { M } & \text { oligo } & \text { oligo } & 2.7 & 0.0 & \text { both } & + \\ & & & & & & & \end{array}$

Fifteen single cases,

discordant for uveitis:

\begin{tabular}{|c|c|c|c|c|c|c|c|}
\hline chronic & M & poly & poly & 1.3 & 3.5 & both & + \\
\hline & M & oligo & oligo & 1.0 & 3.1 & both & - \\
\hline & $\mathrm{F}$ & oligo & oligo & 6.8 & -0.5 & both & - \\
\hline & M & oligo & oligo & 1.8 & 2.6 & right & + \\
\hline & $\mathrm{F}$ & oligo & poly & 1.7 & 0.0 & both & + \\
\hline & $\mathrm{F}$ & poly & poly & 1.9 & 0.3 & both & + \\
\hline & $\mathrm{F}$ & oligo & oligo & 3.4 & 0.6 & left & + \\
\hline & M & poly & poly & 4.8 & 0.1 & both & + \\
\hline & $\mathrm{F}$ & oligo & oligo & 2.1 & 3.1 & both & - \\
\hline & M & oligo & oligo & 6.8 & 0.0 & both & + \\
\hline healed chronic & M & poly & poly & 4.3 & -0.2 & left & - \\
\hline & M & oligo & oligo & 3.4 & 3.2 & both & + \\
\hline & $\mathrm{F}$ & poly & poly & 3.3 & 1.9 & both & + \\
\hline acute & M & $\begin{array}{l}\text { enthesitis } \\
\text { - related }\end{array}$ & $\begin{array}{l}\text { enthesitis } \\
\text { - related }\end{array}$ & 13.3 & -0.8 & left & - \\
\hline & M & $\begin{array}{c}\text { enthesitis } \\
\text { - related }\end{array}$ & $\begin{array}{l}\text { enthesitis } \\
\text { - related }\end{array}$ & 11.3 & -0.8 & right & + \\
\hline
\end{tabular}

*Interval to uveitis denotes the interval between the onset of arthritis and the appearance of uveitis; a negative value indicates that the uveitis was detected previous to diagnosis of arthritis. 
Acute symptomatic anterior uveitis was diagnosed in two boys with oligoarthritis, who later developed enthesitis-related arthritis. The remaining 19 out of 21 siblings with uveitis had the insidious anterior form. In five cases uveitis was diagnosed before (two patients) or at diagnosis (three patients) of JIA. Two children had uveitis of short duration ( $<3$ months) and in 13 cases uveitis persisted at the end of follow-up. Uveitis was bilateral in almost two-thirds of the patients and complicating cataract was detected in eight, secondary glaucoma in one and CME in one. However, the final visual acuity was good (>20/40) in all patients except the one with glaucoma; the right eye had visual impairment to perception of light.

\subsubsection{Occurrence of uveitis in recently diagnosed juvenile idiopathic arthritis (IV)}

In a large cohort of 426 patients with a recent diagnosis of JIA uveitis was detected in 104 cases (24\%) (The designation JCA was used in the original paper according to EULAR criteria). The demographic and disease-related characteristics of these patients are described in Table 8. 
Table 8. Main demographic and disease-related characteristics of JIA patients according to the presentation of uveitis.

\begin{tabular}{|c|c|c|c|}
\hline Characteristics & $\begin{array}{l}\text { JIA with uveitis } \\
\text { n=104 }\end{array}$ & $\begin{array}{l}\text { JIA without uveitis } \\
\qquad \mathrm{n}=322\end{array}$ & $\mathrm{P}$ \\
\hline Male / Female, n (\%) & $35(34)$ / $69(66)$ & $115(36) / 207(64)$ & 0.80 \\
\hline Age at diagnosis of JIA, mean (range) & $4.8(0.6-15)$ & $7.3(0.9-16)$ & $<0.001$ \\
\hline Age at diagnosis of uveitis, mean (range) & $5.9(1.1-17.7)$ & & \\
\hline Interval from JIA to uveitis, mean (range) & $1.1(-2.4-6.5)$ & & \\
\hline Antinuclear antibody positive, n (\%) & $69(66)$ & $119(37)$ & $<0.001$ \\
\hline HLA B27 antigen-positive, n $(\%)^{*}$ & $20 / 74(27)$ & $69 / 202(31)$ & 0.50 \\
\hline Oligoarticular disease type, $\mathrm{n}(\%)$ & $76(73)$ & $207(64)$ & 0.12 \\
\hline \multicolumn{4}{|l|}{ Polyarticular disease type } \\
\hline Rheumatoid factor-negative, n (\%) & $25(24)$ & $77(24)$ & 1.0 \\
\hline Rheumatoid factor-positive, n (\%) & $1(1)$ & $16(5)$ & 0.105 \\
\hline Systemic disease type, $\mathrm{n}(\%)$ & $1(1)$ & $16(5)$ & 0.105 \\
\hline Other types of JIA, n (\%) & $1(1)^{\S}$ & $6(2)^{\#}$ & 0.917 \\
\hline
\end{tabular}

*HLA B27 was not examined in all cases; ${ }^{\S}$ one patient with psoriatic arthritis; ${ }^{*}$ one patient with ulcerous colitis, one with psoriatic arthritis, one with reactive arthritis, and three with spondyloarthropathy

The patients were collected during the years 1989-1996 at the Rheumatism Foundation Hospital and the mean prospective follow-up was 4.5 years for all patients and 5.8 years for those with uveitis. In this series uveitis was detected early on in the course of JIA, a mean 1.1 years from the diagnosis of JIA, the median as short as 0.3 years. The age at the diagnosis of JIA was significantly lower in patients with uveitis than without it and ANA positivity was more frequent among uveitis patients $(\mathrm{P}<0.001)$. 
Proportionally, uveitis was as common among girls as among boys, as well as in patients with oligoarthritis and with RF-negative polyarthritis.

Uveitis was asymptomatic in 99 out of 104 children, including: chronic anterior uveitis in 80, recurrent episodes of uveitis in seven, and uveitis of short duration ( $<6$ months) in 12 patients. Acute anterior uveitis of 4 to 6 weeks' duration was diagnosed in five cases: one HLA B27negative girl and four HLA B27-positive boys. Uveitis was bilateral in $63 \%$ of patients and still active in $61 \%$ at the end of follow-up.

Complications of uveitis were detected in $24 \%$ of cases; of these cataract was the most common. A cataract operation was undertaken in nine cases, in six of them with intraocular lens implantation. The postoperative activity of uveitis was not influenced by the surgical method used (with intraocular lens or without). Secondary glaucoma was refractory to conservative treatment in three patients, who underwent a filtering operation with an implant in two of them.

Of all patients with JIA $12 \%$ and of uveitis patients $49 \%$ developed uveitis before arthritis or within three months from the onset of joint symptoms. In $91 \%$ of JIA-associated uveitis cases uveitis appeared within the first four years after the onset of JIA. The visual prognosis was good: in three children visual acuity decreased to 20/60 or less; none became blind.

Proportional hazard models were used to characterise the determinants of uveitis in those patients with oligoarthritis or polyarthritis among whom uveitis had developed only after the diagnosis of JIA. The only significant determinants of uveitis in this specific group were ANA positivity and early onset of arthritis.

The three different groups of children with uveitis are compared in Table 9. 
Table 9. Comparison of uveitis patients in the three different study populations above

\begin{tabular}{|c|c|c|c|}
\hline Characteristic & $\begin{array}{l}\text { Epidemiological } \\
\text { study } \\
\mathrm{n}=114\end{array}$ & $\begin{array}{l}\text { Sibling } \\
\text { series } \\
n=80\end{array}$ & $\begin{array}{c}\text { Clinic-based } \\
\text { series } \\
n=426\end{array}$ \\
\hline Female, $\%$ & 70 & 61 & 65 \\
\hline Oligoarthritis, \% & 75 & 69 & 66 \\
\hline ANA-positive, $\% *$ & $43(49 / 113)$ & 56 & 44 \\
\hline HLA B27-positive, \%* & $36(24 / 66)$ & 36 & $31(86 / 276)$ \\
\hline RF-positive, $\% *$ & $4(4 / 112)$ & 0 & 4 \\
\hline Uveitis patients, $\%$ & 16 & 26 & 24 \\
\hline Visual loss $<20 / 60$ in eyes with uveitis, $\%$ & 3 & 2 & 4 \\
\hline $\begin{array}{l}\text { Complications of uveitis, } \\
\text { eyes (patients), } \%\end{array}$ & $19(22)$ & $38(38)$ & $22(24)$ \\
\hline $\begin{array}{l}\text { Age at diagnosis of arthritis, mean (range), } \\
\text { yrs }\end{array}$ & $\begin{array}{c}7.4 \\
(1.3 \text { to } 14.3)\end{array}$ & $\begin{array}{c}4.7 \\
(1.0 \text { to } 13.3)\end{array}$ & $\begin{array}{c}6.7 \\
(0.6 \text { to } 16.0)\end{array}$ \\
\hline $\begin{array}{l}\text { Age of uveitis patients, mean, } \\
\text { at diagnosis of arthritis, yrs }\end{array}$ & 6.8 & 4.1 & 4.8 \\
\hline at diagnosis of uveitis, yrs & 9.7 & 5.4 & 5.9 \\
\hline Follow-up, mean, yrs & 7.5 & 6.5 & 4.5 \\
\hline
\end{tabular}

*number tested in parenthesis

In the two hospital-based series uveitis occurred more often and the children were younger at the onset of arthritis than in the population-based study. Complications of uveitis were more common in the children in the sibling series with uveitis, but visual loss was equal in all three groups.

5.2. Uveitis as a marker of active arthritis in 372 patients with juvenile idiopathic seronegative oligoarthritis or polyarthritis (V)

A comparison of the activity of arthritis was made between JIA patients with uveitis and without it in the hospital-based cohort of 426 children with recently diagnosed JIA during a 
mean follow-up of 4.5 years. To enhance the homogeneity of the study series, only patients with rheumatoid factor- negative juvenile oligoarthritis or polyarthritis were included. As a result, the study group comprised 372 children with JIA, of whom 96 had insidious uveitis. The basic data on the patients are presented in Table 10.

Table 10. Basic demographic and clinical data on 372 JIA patients grouped according to the occurrence of uveitis.

\begin{tabular}{|c|c|c|c|}
\hline & $\begin{array}{c}\text { Patients with } \\
\text { uveitis } \\
\text { n=96 }\end{array}$ & $\begin{array}{l}\text { Patients without } \\
\text { uveitis } \\
n=276\end{array}$ & $p$ Value \\
\hline Boys : Girls, n (\%) & $30(31): 66(69)$ & $97(35): 179(65)$ & 0.49 \\
\hline Age at the diagnosis of arthritis ${ }^{\#}$, years & $4.4(3.5)$ & $7.1(4.4)$ & $<0.001$ \\
\hline Age at the diagnosis of uveitis ${ }^{\#}$, years & $5.6(3.4)$ & & \\
\hline \multicolumn{4}{|l|}{ Onset type of arthritis, $\mathrm{n}(\%)$} \\
\hline oligoarthritis : polyarthritis & $71(74): 25(26)$ & $202(73): 74(27)$ & 0.88 \\
\hline Extended type of oligoarthritis ${ }^{\S}, \mathrm{n}(\%)$ & $13(18)$ & $23(11)$ & 0.21 \\
\hline ANA-positive patients, $\mathrm{n}(\%)$ & $67(70)$ & $110(40)$ & $<0.001$ \\
\hline HLA B27-positive patients, $n$ & $16(67$ tested $)$ & $60(184$ tested $)$ & 0.18 \\
\hline \multicolumn{4}{|l|}{$\mathrm{ESR}^{\#}, \mathrm{~mm} / \mathrm{h}$} \\
\hline at the diagnosis of arthritis & $36(25)$ & $28(24)$ & 0.001 \\
\hline at the end of follow-up & $14(12)$ & $11(9)$ & 0.02 \\
\hline \multicolumn{4}{|l|}{ Hemoglobin ${ }^{\#}, \mathrm{~g} / 1$} \\
\hline at the diagnosis of arthritis & $118(11)$ & $121(12)$ & 0.008 \\
\hline at the end of follow-up & $127(10)$ & $129(11)$ & 0.114 \\
\hline \multicolumn{4}{|l|}{ Patients treated with, n (\%) } \\
\hline oral prednisolone & $48(50)$ & $69(25)$ & $<0.001$ \\
\hline methotrexate & $56(58)$ & $113(41)$ & 0.003 \\
\hline glucocorticoid joint injections & $90(94)$ & $188(68)$ & $<0.001$ \\
\hline Patients with remission of arthritis, $\mathrm{n}(\%)$ & $20(21)$ & $116(42)$ & $<0.001$ \\
\hline Follow-up time ${ }^{\#}$, yrs & $5.7(2.2)$ & $4.1(2.2)$ & $<0.001$ \\
\hline
\end{tabular}

${ }^{\#}$ mean (standard deviation); ${ }^{\S}$ oligoarthritis extended to polyarthritis during the course of arthritis 
Laboratory parameters (hemoglobin, ESR), need of systemic and local corticosteroid therapy and use of methotrexate reflected significantly greater inflammatory joint activity in JIA patients with uveitis than without it. The number of inflamed joints was significantly greater at the end of the follow-up in patients with persistent polyarthritis and uveitis compared to those polyarthritis patients without uveitis.

\subsection{Uveitis as a cause of visual loss in arthritides and comparable conditions (VI)}

At the end of 1996 the Finnish Register of Visual Impairment included 174 patients (72 male, 102 female) handicapped after 1980, in whom uveitis was the main cause of visual impairment. An inflammatory rheumatic disease or comparable condition had been detected in $22 \%$ of them. Uveitis in this study resulted in visual loss within an average of 18 years, and visual acuity remained <20/60 in 133 patients (in 41 cases central visual acuity >20/60 after effective medical and surgical treatment of uveitis). 
Table 11. Age at onset of etiologic disease or comparable condition and at diagnosis of uveitis, and years up to handicapping from the onset of uveitis

\begin{tabular}{|c|c|c|c|c|c|c|c|}
\hline \multirow[t]{2}{*}{ Etiologic disease } & \multirow[t]{2}{*}{$\begin{array}{c}\text { Patients, } \\
\text { n }\end{array}$} & \multicolumn{2}{|c|}{$\begin{array}{c}\text { Age at diagnosis } \\
\text { of etiologic } \\
\text { disease, yrs }\end{array}$} & \multicolumn{2}{|c|}{$\begin{array}{l}\text { Age at diagnosis } \\
\text { of uveitis, yrs }\end{array}$} & \multicolumn{2}{|c|}{$\begin{array}{c}\text { Years up to } \\
\text { handicapping }\end{array}$} \\
\hline & & Mean & Range & Mean & Range & Mean & Range \\
\hline JIA & 14 & 9 & 1 to 30 & 11 & 3 to 30 & 11 & 1 to 41 \\
\hline AS & 7 & 36 & 15 to 60 & 32 & 22 to 46 & 22 & 12 to 34 \\
\hline $\operatorname{ReA}$ & 3 & 42 & 29 to 60 & 48 & 29 to 65 & 6 & 0 to 16 \\
\hline RF-negative arthritis & 4 & 22 & 15 to 24 & 29 & 17 to 52 & 19 & 5 to 47 \\
\hline SLE & 1 & 8 & & 9 & & 0 & \\
\hline PAN & 1 & 59 & & 27 & & 37 & \\
\hline PM & 1 & 24 & & 24 & & 9 & \\
\hline Beçhet's disease & 2 & 27 & 22 to 31 & 27 & 23 to 31 & 2 & 1 to 2 \\
\hline Sarcoidosis & 5 & 53 & 26 to 87 & 43 & 13 to 82 & 17 & 0 to 55 \\
\hline Toxoplasma choroiditis & 10 & NA & & 19 & 0 to 71 & 31 & 0 to 70 \\
\hline Tuberculous choroiditis & 8 & NA & & 23 & 10 to 34 & 37 & 14 to 60 \\
\hline $\begin{array}{l}\text { Miscellaneous other } \\
\text { diseases }\end{array}$ & 20 & NA & & 37 & 1 to 78 & 15 & 0 to 55 \\
\hline Back pain/arthralgia & 15 & 43 & 14 to 68 & 49 & 5 to 68 & $7 *$ & -3 to 26 \\
\hline Trauma/surgery & 9 & NA & & 46 & 2 to 92 & $14^{*}$ & -1 to 46 \\
\hline No established etiology & 74 & NA & & 40 & 0 to 78 & $19^{*}$ & -7 to 66 \\
\hline All patients & 174 & NA & & 36 & 0 to 92 & $18^{*}$ & -7 to 70 \\
\hline
\end{tabular}

* Negative years mean that visual impairment was in some cases detected before diagnosis of uveitis. Abbreviations: AS, ankylosing spondylitis; ReA, reactive arthritis; SLE, systemic lupus erythematosus; PAN, polyarteritis nodosa; PM, polymyalgia rheumatica; NA, not available.

As seen in Table 11, JIA was the largest single group of inflammatory rheumatic diseases, causing uveitis in 14 out of $174(8 \%)$ patients. In $8(57 \%)$ cases of JIA visual acuity remained permanently impaired $<20 / 60$. 
Ankylosing spondylitis and reactive arthritis had been diagnosed in seven and three patients, respectively. Visual loss occurred in a markedly shorter time in the latter than in the former disease group (6 versus 22 years). In the four RF-negative RA cases found visual impairment developed within a mean 19 years from the diagnosis of uveitis. One young girl fell ill with systemic lupus erythematosus at the age of eight and was rapidly blinded with complicating herpes zoster uveitis. Uveitis with Beçhet's disease in two young men caused severe visual loss within months. Sarcoidosis was associated with uveitis in five patients and polyarteritis nodosa and polymyositis in one each. An additional 15 patients had back pain/arthralgia but in none of them could an inflammatory rheumatic disease be established. In 74 of 174 (43\%) patients the etiology of uveitis remained unknown.

Uveitis resulted in visual impairment after a mean of 18 years and in $22 \%$ of patients an associated inflammatory rheumatic disease or comparable condition could be identified. 


\section{DISCUSSION}

\subsection{Discussion of patients and methods}

\subsubsection{Genetic background of the Finnish population}

Although the majority of Europeans speak Indo-European languages, about 24 million speak Finno-Ugric languages such as Hungarian, Finnish, and Estonian. Based originally on the linguistic relationship of Finnish with languages spoken by certain ethnic groups in Russia, it has traditionally been thought that the Finns migrated to their current location from a common origin in the East, either in the Altai, the Ural, or the Volga region. Studies of nuclear gene frequencies, however, have shown that the greater proportion of the Finnish gene pool is "European", even though Finns appear to differ from other European populations more than Europeans in general differ from each other (Nei and Roychoudhury 1982, Virtaranta-Knowles et al 1991). Studies on mitochondrial DNA sequences have revealed that European populations, including Finns, are part of one homogeneous mitochondrial gene pool. Quite recently, however, y chromosome haplotype variation has provided evidence for a substantial paternal genetic contribution of Asians to the Finns (Zerjal et al 1997, Kittles et al 1998).

\subsubsection{Sensitivity of the sickness insurance register}

The Finnish nation-wide sickness insurance scheme covers the entire population. On the basis of the drug reimbursement register (a part of the Social Insurance Institution's population register), it is possible to estimate the occurrence of chronic rheumatic diseases. In a community with 18000 inhabitants, 218 adult subjects with chronic rheumatic diseases had been registered for drug reimbursement and only two additional subjects with these disorders were found outside the register (Hakala et al 1993). In a nation-wide series of subjects with RA who had died in 1989, 95\% of those in whom RA was mentioned in the death certificate had been entitled to specially reimbursed medication (Myllykangas-Luosujärvi et al 1995). Thus the sensitivity of the register as an inclusion criterion concerning patients with RA is good. Less information is available in the case of JIA. In a series of 47 pediatric patients, however, only one was not eligible for drug reimbursement (Savolainen and Isomäki 1993). 


\subsubsection{The study populations}

6.1.3.1. Population-based study of uveitis in juvenile idiopathic arthritis

The incidence of JIA as assessed on the grounds of the drug reimbursement register was found to be 14/100 000 in the pediatric population (Kaipiainen-Seppänen and Savolainen 1996). This figure is in agreement with those in other studies from countries from which reliable information is available (Andersson Gäre 1999).

The occurrence of uveitis was examined in this population-based cohort of JIA patients. All the 114 JIA patients in this series (II) had been treated at their district central hospitals or at the Rheumatism Foundation Hospital, and accordingly patient records were readily available. The majority of these children had been examined by an ophthalmologist at the onset of JIA and thereafter one to two times a year for several years (43/114 patients were examined by the same ophthalmologist at the Rheumatism Foundation Hospital at least once). Evidently most, if not all, of the uveitis cases in the patient series could be identified.

\subsubsection{Uveitis in patients with a recent diagnosis of juvenile idiopathic arthritis}

The clinic-based study of uveitis in patients with recently diagnosed JIA (IV) was carried out at the Rheumatism Foundation Hospital, Heinola, Finland, where close co-operation with an ophthalmologist and pediatric rheumatologists is well organised (annually JIA patients require more than 1100 consultations with an ophthalmologist). As stated, the annual incidence of JIA in Finland is 14/100 000 (Kaipiainen-Seppänen and Savolainen 1996), this figure corresponding to 150 new cases of JIA. One third of these are seen at the Rheumatism Foundation Hospital in the early phase of their disease and they have been examined by the ophthalmologist. The group is presumed to be representative of the newly diagnosed JIA patients from central parts of Finland.

\subsubsection{Uveitis in sibling pairs with juvenile idiopathic arthritis}

The genetic study series (III) comprised 80 JIA patients from 37 families with two or three JIA children. The index cases and the majority of their siblings were found among about 2000 JIA patients seen at the Rheumatism Foundation Hospital during a period of 15 years. In addition to 
patients seen at the Hospital from the outset, there were also patients referred to the Hospital at a later phase because of sustained disease difficult to manage, for surgery, or for rehabilitation. Thus, the sibling series might have been to some degree selected. However, apart from their earlier age at onset, the siblings with JIA did not differ from JIA cases in the population basedseries (Säilä et al 2001).

\subsubsection{Uveitis as a cause of visual loss in arthritides and comparable conditions}

The role of rheumatic diseases or comparable conditions in the etiology of severe uveitis was examined on the basis of the Finnish Register of Visual Impairment. The register was founded in 1983 but remains incomplete. However, during recent years the annual number of new cases of visual handicap in different age groups has remained stable. The coverage is probably better for new cases than for those blinded decades earlier. It is reasonable to assume that young patients are recorded in the Register more frequently than older ones. On the other hand, due to the age wave, the proportion of senile macular degeneration is continuously increasing as a leading cause of visual handicap. In spite of its shortcomings, the register provided a basis for evaluation of visual loss caused by uveitis in rheumatic diseases and comparable conditions. The available patient records were checked. The information regarding patients blinded before 1980 was often incomplete and thus only those whose visual loss was detected during the years 1980 to 1996 were included in the study.

\subsection{Discussion of results}

\subsubsection{Occurrence of uveitis in juvenile idiopathic arthritis}

Most previous studies on uveitis in JIA come from special pediatric or ophthalmologic clinics, and the duration of follow-up periods has varied greatly. Only a few studies have been truly prospective (Spalter 1975, Chylack et al 1975, Michels et al 1987, Kanski 1988, Andersson Gäre and Fasth 1995). By far the largest series of JIA-associated uveitis was reported by Kanski (1988). It consisted of 315 clinic-based cases. Only a small proportion of the patients had been followed prospectively from onset but the vast majority of them were examined personally by the author. 
Studies from ophthalmologic clinics tend to be biased toward the more severe cases of uveitis. Children with mild uveitis are frequently managed by ophthalmologists in the community, and only complicated, difficult-to-manage patients are referred to the academic centres. On the other hand, studies from pediatric clinics are similarly likely to be biased toward the more severe cases of arthritis. Only a few epidemiological surveys have been published (Towner et al 1983, Kunnamo et al 1986, Andersson Gäre and Fasth 1995, Moe and Rygg 1998) and none of these has dealt with uveitis from an ophthalmologist's point of view.

In the present study the occurrence of JIA-associated uveitis was examined on the basis of three different study series: population-based (II), genetic (III) and clinic-based (IV). Uveitis was found in $16 \%, 26 \%$ and $24 \%$ of patients, respectively.

The clinic-based series was large enough to provide a reliable estimate of the frequency of uveitis (24.4\%; 95\% CI 20.3-28.5). The mean prospective follow-up period was 4.5 years (range 0-9.7 years), although for some cases it remained shorter. Although uveitis is detected in the great majority of JIA patients within the first five years of arthritis, in some cases it is a late manifestation. Due to the somewhat too short follow-up period the observed figure may underestimate the true occurrence of uveitis. On the other hand the ophthalmological consultations were regular and in the vast majority of cases conducted by the same ophthalmologist; thus, mild and even transient cases of uveitis could also promptly be found. The interval from the onset of arthritis to the emergence of uveitis in our series was among the shortest so far reported. In this context it is of interest to note that in another large clinic-based series from Finland with a mean follow-up as long as 15 years, 23\% of the 173 JIA patients developed uveitis (Ylijoki 1998).

The frequency of uveitis was somewhat lower $(15.8 \%$; 95\% CI 9.1-22.5) in the populationbased series (II). However, due to the small number of cases it cannot be taken for granted that the found difference between the clinic and population studies was real. On the other hand, our figure is in agreement with those reported from northern Norway (14\%) (Moe and Rygg 1998) and from south-western Sweden, where Andersson Gäre and Fasth reported figures of 9\% and $15 \%$ in their two groups of JIA patients (Andersson Gäre and Fasth 1995). Kunnamo and associates in their community-based study from the Helsinki area in Finland reported uveitis in $21 \%$ of JIA patients. The total number of patients was small and the follow-up period was short (Kunnamo et al 1986). In another community-based study from Minnesota only 2 of 49 (4\%) of 
patients were reported to have uveitis (Towner et al 1986). However, not all patients had been examined by an ophthalmologist. In all the earlier community-based studies only figures concerning the occurrence of uveitis were reported. Our study II is unique in that ocular manifestations were managed from the point of view of an ophthalmologist.

As pointed out in the literature review, there is some evidence that JIA associated-uveitis might occur less frequently in the USA than in England and the Scandinavian countries. In a recent large series from the Philadelphia area (Candell Chalom et al 1997) only 9\% of patients had uveitis. The nucleus of the white population of the United States is from the British Isles. After the Civil War, however, most new migrants were from southern, south-eastern and eastern parts of Europe and in many areas offspring of these migrants outnumber those of the original settlers. No good figures are available from southern and eastern Europe on the occurrence of JIA and uveitis associated with it. Thus, it is not possible to draw conclusions as to the underlying reasons (genetic versus environmental) for the transatlantic difference in the occurrence of uveitis.

\subsubsection{Determinants associated with development of uveitis in juvenile idiopathic arthritis.}

It is a common belief that uveitis in JIA is most frequent in ANA-positive girls with oligoarthritis, arising at ages between 2 and 4 years. Although in our clinic-based cohort of 426 newly diagnosed JIA cases (IV) there were more girls than boys, uveitis was found proportionally as equally in both genders. Likewise, uveitis was associated as often with oligoarthritis as with polyarthritis. To study in greater detail the determinants associated with the development of uveitis we used a proportional hazard model for patients among whom uveitis had developed after the diagnosis of JIA. The only significant determinants for uveitis proved to be young age and ANA positivity.

It has been assumed that genetic factors play only a modest role in the etiology of JIA. Our recent data, however, would indicate that the genetic component in JIA is more important than previously believed (Savolainen et al 2000). To assess the role of genetic factors specifically associated with the development of uveitis, we observed the occurrence and characteristics of uveitis in sibling pairs with JIA (III). Only three pairs were concordant for the presence of uveitis, the expected number being 3.4. The series reported by Clemens and colleagues (1985) consisted of 12 sibling pairs. Four of them were concordant for the presence of uveitis, and on 
the basis of data given in their paper the expected number was 2.5. Moroldo and associares (1997) reported on a total of 71 sibling pairs. Three pairs were concordant, the expected number was 1.3. Taken together, the data gathered lend little support for the concept of an appreciably heightened sibling recurrence ratio in the etiology of uveitis.

The exact relationship between uveitis and JIA is not known. HLA B27-associated acute anterior uveitis occurs not infrequently in conjunction with symptoms and signs of spondyloarthropathy. However, perhaps even in the majority of patients with this type of uveitis there is no evidence of an underlying rheumatic disease (Rothova et al 1987, Huhtinen and Karma 2000). The association of uveitis and JIA is closer. For example, in a Finnish-population based survey of uveitis in children the uveitis cases associated with JIA outnumbered those with "idiopathic" chronic anterior uveitis (Päivönsalo-Hietanen et al 2000).

\subsubsection{Complications and treatment of uveitis in juvenile idiopathic arthritis}

The most common complications in our series were cataract, glaucoma, CME and band keratopathy. Of these, band keratopathy always results from inflammation, whereas cataract and glaucoma can also result from treatment, and CME from surgery, e.g. cataract extraction. In this regard it is of interest to note that as many as $14 \%$ of JIA patients without uveitis in our clinic-based series (IV) developed cataract; all had received systemic corticosteroids, whereas none of those who had not received systemic corticosteroids developed cataract. None of the patients without uveitis had glaucoma. In the long-term follow-up study of JIA patients by Ylijoki (Ylijoki 1998), 4 of 173 patients had impaired vision. In two cases this was attributable to uveitis and in two cases to cataract induced by corticosteroid treatment.

During the last 20 years the prognosis of JIA patients has improved as a result of effective medical and surgical treatment of the arthritis and better treatment of severe uveitis (Cabral et al 1994, Tugal-Tutkun et al 1996, Dana et al 1997, Nguyen and Foster 1998) (Table 12). 
Table 12. Decreasing severity of uveitis in patients with JIA and uveitis

\begin{tabular}{|c|c|c|c|c|c|}
\hline & $\begin{array}{c}\text { Cassidy } \\
\text { et al } \\
1977\end{array}$ & $\begin{array}{l}\text { Wolf } \\
\text { et al } \\
1987\end{array}$ & $\begin{array}{c}\text { Cabral } \\
\text { et al } \\
1994\end{array}$ & $\begin{array}{c}\text { Candell Chalom } \\
\text { et al } \\
1997\end{array}$ & $\begin{array}{c}\text { Kotaniemi } \\
\text { et al } \\
2001\end{array}$ \\
\hline Number of patients, $\mathrm{n}$ & 38 & 51 & 49 & 71 & 104 \\
\hline (Affected eyes, $n$ ) & & (89) & $(82)$ & & $(170)$ \\
\hline Mean follow-up, years & 4.8 & 12.7 & 9.4 & NA & 5.8 \\
\hline \multicolumn{6}{|c|}{ Visual impairment $(<20 / 50)$} \\
\hline Patients, n (\%) & $14(37)$ & & & $8(11)$ & $4(4)$ \\
\hline Eyes, n (\%) & & $35(39)$ & $12(15)$ & & $8(5)$ \\
\hline
\end{tabular}

Abbreviation: NA, not available

It is possible that the combination of corticosteroids with methotrexate and/or cyclosporine (I) or azathioprine or other immunosuppressive medications has made for improved visual prognosis in uveitis patients.

In the present clinic-based series (IV) complicating cataract was found in 22 of 104 JIA patients with uveitis and it was operated in nine cases (intraocular lens implantation in six).

New cataract surgery techniques are helpful in visual rehabilitation of children with JIA, but the role of intraocular lens implantation in uveitic eyes is still controversial (Foster and Barrett 1993, BenEzra and Cohen 2000). It is recommended to concentrate surgery on JIA children with uveitis in experienced hands (Kanski and Petty 1996, Nguyen and Foster 1998).

Secondary glaucoma is often refractory to medical treatment. Operative treatment of glaucoma has also altered during the last 20 years; glaucoma implant devices have shown good results in JIA in cases with secondary glaucoma refractory to medical treatment (Välimäki et al 1997). In the series of 104 JIA patients with uveitis here (IV), a glaucoma operation was needed in three cases (with a filtering implant device in two). In some children secondary glaucoma can be managed with laser treatment and/or conventional filtering surgery with or without local 
antimetabolites (e.g. fluorouracil or mitomycin). The operative treatment should not be postponed too far (Kanski and Petty 1996).

CME is a severe complication of uveitis and must be treated promptly and actively. Systemic corticosteroids and/or local corticosteroid injections are the first choice, but good control of uveitis in the long run is mandatory. In sight-threatening situations the use of immunosuppressive and immunomodulatory drugs must be considered (Nguyen and Foster 1998).

The prevalence of severe band keratopathy in our study (IV) was lower than previously reported, which may reflect earlier detection and more effective present treatment of uveitis than two decades ago (Sherry et al 1991).

In fact, during earlier decades the visual prognosis of patients with uveitis has been markedly poorer than at present (Kanski 1977, 1981, Cabral et al 1994). Nevertheless, our study based on the Finnish Register of Visual Impairment in 1980-1996 (VI) showed that uveitis caused 3\% of visual impairment and the most prominent single group (14 out of 174 cases) comprised patients with JIA- associated uveitis. Also in a Dutch study of the causes of blindness in patients with intraocular inflammatory diseases, JIA was the most frequent systemic disease leading to visual handicap (Rothova et al 1996), the second being sarcoidosis.

\subsubsection{Association of uveitis and arthritis in juvenile idiopathic arthritis.}

It is commonly thought that uveitis and arthritis in JIA run a different course and that the articular prognosis of children with oligoarthritis is good (Rosenberg and Oen 1986, Kanski and Petty 1996). Our conception is that uveitis is a part of the disease process rather than a complication of JIA; accordingly the treatment of uveitis should follow the same rules as that of JIA. In clinical work one gets an impression that JIA children with refractory uveitis frequently also have very active arthritis and improvement in uveitis - as in the case of our patient (I) - is achieved only through the control of arthritis.

To our knowledge only one study hitherto has specifically addressed the question of the articular prognosis of JIA patients with uveitis (Cimaz and Fink 1996). In the study in question 
29 patients with uveitis and 86 control cases were compared. There too the patients with uveitis managed worse regardless which one of the four indicators was applied.

We studied the association between the clinical activity of arthritis and the occurrence of uveitis by utilising our large cohort of 372 seronegative (out of a total of 426) newly diagnosed JIA patients with oligoarthritis or polyarthritis (V). ESR and CRP values, the routinely used laboratory acute-phase measures mirroring clinical disease activity, were statistically significantly higher in JIA patients with uveitis than in cases without. The number of inflamed joints was significantly greater at the end of the follow-up in patients with persistent polyarthritis and uveitis compared to those polyarthritis patients without uveitis. Further, methotrexate and systemic corticosteroid treatment as well as the need of local corticosteroid joint injections were more frequent in the group of patients with uveitis.

As discussed above, the present series may be taken to be fairly representative of recently diagnosed cases of JIA from central parts of Finland and in our opinion the observed association between the severity of arthritis and uveitis is genuine and not a consequence of biased patient selection.

\subsubsection{Uveitis as a cause of visual loss in arthritides and comparable conditions.}

The etiology of blinding uveitis was examined using information from the Finnish Register of Visual Impairment. Special problems occur with uveitis. Its sequelae such as cataract and glaucoma may be considered the cause of visual loss while the primary cause (uveitis) has not been mentioned (Rothova et al 1996). This error is likely to occur more frequently in idiopathic uveitis cases than in those with established etiology or with well-known disease associations.

Chronic insidious uveitis is a prominent manifestation of JIA. It is usually bilateral and asymptomatic. If not detected early and properly treated, it can result in substantial morbidity and even blindness (Rothova et al 1987, Kanski 1990, Candell Chalom et al 1997, Dana et al 1997).

Uveitis occurring in conjunction with the HLA B27 allele is a distinct clinical entity characterised typically by acute, unilateral, recurrent attacks of iridocyclitis (Wakefield et al 1991, Rodriguez et al 1994). This allele occurs in Finns more frequently (14\%) than in most other populations of European origin. Occasionally, the inflammation becomes chronic, 
resulting in sight-impairing complications (cataract, glaucoma, CME and band keratopathy). There is occasional evidence that severe eye disease is more likely to accompany reactive arthritis than ankylosing spondylitis (Youssef and Russell 1990, Rodriguez et al 1994, Calin 1998). To our knowledge, however, no patient series has been published.

A rheumatic disease or comparable condition was found in the etiology of severe uveitis in $22 \%$ in our series of 174 uveitis patients with visual loss established during 1980-1996; earlier cases were excluded. Thus, this material constitutes a cumulative incidence series rather than a prevalence series. About one-third of the patients had some rheumatic complaints. JIA was the most prominent group, consisting of 14 patients, all of whom had longstanding disease. Most likely the diagnosis of uveitis in these patients had been delayed.

The four patients diagnosed as having seronegative RA may equally well have been suffering from spondyloarthropathy with predominant peripheral joint involvement. On the other hand, one of these patients had most probably contracted her disease before the age of 16 and could thus be classified in the JIA group as well. Further, some of the cases with ill-defined back problems may also have been suffering from spondyloarthropathy. Interestingly, in half of the patients with spondyloarthropathies uveitis was insidious at onset and ran a chronic course instead of being acute and symptomatic. This is obviously due to selection of patients with poor prognosis of their rheumatic disease in this cohort.

The number of patients with sarcoidosis was appreciably lower than that of patients with JIA and spondyloarthropathies. In this respect our study differs from an earlier report where sarcoidosis was among the most frequent causes of blinding uveitis (Rothova et al 1996).

Most of the uveitis patients in the present series represent treatment failures from a period prior to 1980. Systematic screening for patients with JIA was instituted in Finland in the late 1970s. However, the prognosis of uveitis is considered to be better today than it was a few decades ago owing to effective medication and better conventional and surgical treatment of both arthritis and uveitis.

Our study provides population-based data on visual handicap associated with different uveitis entities. The importance of the search for the etiology of the systemic disease associations of uveitis cannot be overestimated. 


\section{RECOMMENDATIONS CONCERNING THE SCREENING AND MANAGEMENT OF UVEITIS ASSOCIATED WITH JUVENILE IDIOPATHIC ARTHRITIS}

Uveitis in JIA is frequently chronic and the treatment remains unsatisfactory (I). In early phases it is difficult to detect the few small cells in the anterior chamber or faint aqueous flare in a poorly cooperating child. Repeated control examinations are technically easier to carry out if the ophthalmologist and the staff are familiar with child and parents. On the other hand, through repeated re-examinations during follow-up the ophthalmologist becomes acquainted with the individual features of uveitis in each patient, which facilitates the planning of management in the long run.

The mainstay in the treatment of uveitis is the strict control of inflammation. Therapy is discontinued step by step and the eyes have to be repeatedly re-examined, since prompt observation of a relapse and reinstitution of therapy is a must. The timely treatment of complications of uveitis, cataract and glaucoma, is important. Corticosteroid treatment has to be balanced delicately, since both uveitis as a process, but also corticosteroids given as therapy are cataractogenic. This concerns especially children with systemic onset JIA, who are frequently treated with large doses of corticosteroids for months or even years and thus are at an increased risk of developing cataract.

The phacoemulsification of the cataract with intracapsular lens implantation combined with anterior vitrectomy and opening of the posterior capsule via the pars plana is a method frequently used today. The cataract operation should not be postponed too far, in view of the risk of amblyopia. The visualisation of the fundus of the eye is also important in order to find possible complicating $\mathrm{CME}$ in time, as well as to evaluate the optic disc for possible glaucomatous changes.

Medical treatment of uveitis-associated secondary glaucoma is often unsuccessful. Cyclodestruction with cryo- or laserapplication may result in the control of glaucoma, as well 
as other surgical methods such as trabeculectomy and filtering phlebs. One must not forget that about $10 \%$ of persons are corticosteroid responders; increased ocular pressure is a consequence of local, or to a lesser extent of systemic corticosteroid treatment.

Aggressive treatment of both arthritis and uveitis from the very beginning of the joint and eye disease would appear to be important. The fear of side-effects of the drugs ought not to be an obstacle to effective treatment if the uveitis is sight-threatening. From a clinician's perspective, active arthritis seems to be associated with ongoing uveitis (V). Continuous monitoring of such cases by experienced ophthalmologists in close co-operation with pediatric rheumatologists is essential in saving the sight of these patients. (Nguyen and Foster 1998).

Careful ophthalmologic screening for uveitis in children with JIA is recommended:

1. Every 3-4 months in early-onset oligoarthritis or RF-negative polyarthritis for the first two years, then twice yearly until the age of 16 , then every 2 nd-3rd year for several years.

2. Twice a year in RF-positive polyarthritis and systemic onset JIA until the age of 12, then yearly until the age of 16 .

3. Young children (<4 years) with ANA-positive oligoarthritis or polyarthritis run the greatest risk of contracting uveitis. They should be regularly examined by an experienced ophthalmologist at least four times a year two years and then twice a year for the first four years of arthritis.

4. Children with active and refractory uveitis and arthritis should be monitored by the same team of ophthalmologists and pediatric rheumatologists in order to establish optimal management for both arthritis and uveitis of each individual. 


\section{ACKNOWLEDGEMENTS}

This study was carried out during the years 1996-2001 at the Rheumatism Foundation Hospital, Heinola, Finland, in cooperation with the Department of Ophthalmology, Helsinki University Hospital, Helsinki, Finland.

I want to express my gratitude to Professor Martti Nissilä and to Managing Director Hannele Kalske for giving me the opportunity to carry out this study at the Rheumatism Foundation Hospital.

I am sincerely grateful to Professor Leila Laatikainen, Head of the Department of Ophthalmology, Helsinki University Hospital allowing me to perform this work in association with the university clinic.

I wish to express my deepest gratitude to my supervisor Professor Kimmo Aho of the National Public Health Institute, for acting as principal supervisor and the prime mover of my study. Docent Anni Karma has been my ophthalmologic counsellor and I owe her my warmest thanks. Both of my supervisors have been patient and tireless in introducing me to the world of scientific work and without their support this undertaking could not have been carried through.

My thanks go also to Docent Kaija Tuppurainen from the Ophthalmologic Department of Kuopio University Hospital and Rheumatologist Docent Pekka Hannonen, Head of the Medical Department of Jyväskylä Central Hospital, for reviewing my work and making fruitful comments.

Docent Anneli Savolainen, Doctors Oili Kaipiainen-Seppänen and Hanna Säilä, and Professor Marjatta Leirisalo-Repo have been my co-workers and I am most grateful to them for their kind support and encouragement during my study. Mr Hannu Kautiainen, the statistician, has been a very important co-worker and I wish to acknowledge my debt to him.

Through the kind collaboration of the staff of the children's ward of the Department of Pediatrics at the Rheumatism Foundation Hospital under the leadership of Paediatric Rheumatologist Jarkko Haapasaari this study was possible. I am sincerely grateful to all of 
them. I wish to extend my warmest thanks to all the children involved in this study for their collaboration throughout.

In the practical work of studying the children my closest workmate and friend has been Mrs Anneli Jäppinen, with whom I have shared many joys and sorrows of life during this study. I am deeply grateful to her.

I wish to thank Mrs Kristiina Sihto-Kauppi, my colleague and my good friend, for standing in for me at work during my leave of absence. Without her kind help completion of this thesis could have lasted much longer.

I also want to express my gratitude to Docent Riitta Myllykangas-Luosujärvi for introducing me to my supervisor Professor Kimmo Aho in connection with her own dissertation. That was the first step towards this undertaking of mine.

I wish to thank Mrs Pirjo Mäkelä, Mrs Mirja Rekola and Mrs Pirjo Mäki for their help during the project.

Mrs Outi Meriläinen and Mr Robert MacGilleon have been the revisers of my English and I am deeply indebted.

I acknowledge the Social Insurance Institution and the Finnish Register of Visually Impaired for collecting material of this study, as well as the friendly cooperation of the hospitals in the study area.

My husband and colleague Antero has been also my co-worker, and without his love and support this study would have been much more difficult to me. Our beloved children Anne, Laura, and Miika have given me their warm support and I am very grateful to them.

This research was financially supported by Sokeain Ystävät ry and the Rheumatism Research Foundation.

Heinola, October 2001 Kaisu Kotaniemi 


\section{REFERENCES}

Andersson Gäre B. Juvenile arthritis - Who gets it, where and when? A review of current data on incidence and prevalence. Clin Exp Rheumatol 1999;17:367-74.

Andersson Gäre B, Fasth A. Epidemiology of juvenile chronic arthritis in South-western Sweden: A 5-year prospective population study. Pediatrics 1992;90:950-8.

Andersson Gäre B, Fasth A. -The natural history of juvenile chronic arthritis: A population based cohort study. 1. Onset and disease process. J Rheumatol 1995;22:295-307.

Andersson Gäre B, Fasth A, Andersson J, Berglund G, Ekström H, Eriksson M, Hammaren L, Holmquist L, Ronge E, Thilen A. Incidence and prevalence of juvenile chronic arthritis. Ann Rheum Dis 1987;46:277-81.

Ansell BM, Bywaters FG. Prognosis in Still's disease. Bull Rheum Dis 1959;9:189-92.

BenEzra D, Cohen E. Cataract surgery in children with chronic uveitis. Ophthalmology 2000; 107:1255-60.

Blegvad O. Iridocyclitis and disease of the joints in children. Acta Ophthalmol 1941;19:219-36.

Bloch-Michel E, Nussenblatt R. International Uveitis Study Group recommendations for the evaluation of intraocular inflammatory disease. Am J Ophthalmol 1987;103:234-5.

Boone MI, Moore TL, Cruz OA. Screening for uveitis in juvenile rheumatoid arthritis. J Pediatr Ophthalmol Strabismus 1998;34:41-3.

Brewer EJ Jr, Bass J, Baum J, Cassidy JT, Fink C, Jacobs J, Hanson V, Levinson JE, Schaller J, Stillman JS. Current proposed revision of JRA criteria. Arthritis Rheum 1977; Vol 20 (suppl):195-9.

Cabral DA, Petty RA, Malleson PN, Ensworth S, McGormick AQ, Shroeder M-L. Visual prognosis in children with chronic anterior uveitis and arthritis. J Rheumatol 1994;21:2370-5.

Calabro JJ, Parrino GR, Atchoo PD, Marchesano JM, Goldberg LS. Chronic iridocyclitis in juvenile rheumatoid arthritis. Arthritis Rheum 1970;13:406-13.

Calin A. Spondyloarthropathies. In: Maddison PJ, Isenberg DA, Woo P, Glass DN, editors. Oxford Textbook of Rheumatology. Vol 2. 2nd ed. Oxford, New York, Tokyo: Oxford Medical Publications:1998:5-6:1037-49. 
Candell Chalom E, Goldsmith DP, Koehler MA, Bittar B, Rose CD, Ostrov BE, Keenan GF. Prevalence and outcome of uveitis in a regional cohort of patients with juvenile rheumatoid arthritis. J Rheumatol 1997;24:2031-4.

Cassidy TJ. Juvenile rheumatoid arthritis. In: Kelley WN, Harris ED, Ruddy S, Sledge CB, eds. Textbook of Rheumatology, 4.ed. Philadelphia: Saunders 1993:1189-208.

Cassidy JT, Levinson JE, Bass JC, Baum J, Brewer EJ Jr, Fink CW, Hanson V, Jacobs JC, Masi AT, Schaller JC, Fries JF, McShane D, Young D. A study of classification criteria for a diagnosis of juvenile rheumatoid arthritis. Arthritis Rheum 1986;29:274-81.

Cassidy JT, Levinson JE, Brewer JE. The development of classification criteria for children with juvenile rheumatoid arthritis. Bull Rheum Dis 1989;38:1-7.

Cassidy JT, Sullivan DB, Petty RE. Clinical patterns of chronic iridocyclitis in children with juvenile rheumatoid arthritis. Arthritis Rheum 1977;20 Suppl:224-7.

Chylack LT Jr. The ocular manifestations of juvenile rheumatoid arthritis. Arthritis Rheum 1977;20:217-23.

Chylack LT Jr, Bienfang DC, Bellows R, Stillman JS. Ocular manifestations of juvenile rheumatoid arthritis. Am J Ophthalmol 1975;79:1026-33.

Cimaz RG, Fink CW. The articular prognosis of pauciarticular onset juvenile arthritis is not influenced by the presence of uveitis. J Rheumatol 1996;23:357-9.

Clemens LE, Albert E, Ansell BM. Sibling pairs affected by chronic arthritis of childhood: evidence for a genetic predisposition. J Rheumatol 1985;12:108-13.

Crawford MH, Ginter EK, Evgrafov OV, Tyler-Smith C. Genetic relationships of Asians and northern Europeans, revealed by y-chromosomal DNA analysis. Am J Hum Genet 1997;60:117483.

Dana MR, Merayo-Lloves J, Schaumberg DA, Foster CS. Visual outcome prognosticators in juvenile rheumatoid arthritis-associated uveitis. Ophthalmology 1997;104:236-44.

ten Doesschate J. Causes of blindness in the Netherlands. Doc Ophthalmol 1982;52:279-85.

Dollfus H. Eye involvement in children's rheumatic diseases. Bailliere's Clin Rheumatol 1998;12:309-18. 
Donn RP, Ollier WER. Juvenile chronic arthritis - a time for change? Eur J Immunogenet 1996;23:245-60.

Dunn JP. New treatments for anterior uveitis. Ophthalmology 1996;103:355-6.

Flat $\phi$ B, Aasland A, Vinje O, Forre O. Outcome and predictive factors in juvenile rheumatoid arthritis and juvenile spondyloarthropathy. J Rheumatol 1998;25:366-75.

Forrester JV. Uveitis: pathogenesis. Lancet 1991;338:1498-501.

Foster CS, Barrett F. Cataract development and cataract surgery in patients with juvenile rheumatoid arthritis-associated iridocyclitis. Ophthalmology 1993;100:809-17.

Franceschetti A, Blum JD, Barnatter F. Diagnostic value of ocular symptoms in juvenile chronic polyarthritis (Still's disease). Trans Ophthalmol Soc UK 1951;71:17-27.

Friedlander A. 2 tilfaelde af chronisk septisk polyarthritis in barnealderen med $\varnothing$ jencomplicationer. Ugeskr Laeg 1933;95:1190-4.

Gao X, Fernandez-Vina M, Olsen NJ, Pincus T, Stastny P. HLA-DPB1*0301 is a major risk factor for rheumatoid factor-negative adult rheumatoid arthritis. Arthritis Rheum 1991;34:131012.

Giannini EH, Malagon CN, van Kerckhove C, Taylor J, Lovell DJ, Levinson JE, Passo MH, Ginsberg J, Burke MJ, Glass DN. Longitudinal analysis of HLA associated risks for iridocyclitis in juvenile rheumatoid arthritis. J Rheumatol 1991;18:1394-7.

Glass DN, Giannini EH. Juvenile rheumatoid arthritis as a complex genetic trait. Arthritis Rheum 1999;42:2261-8.

Goldbach-Mansky R, Lee J, McCoy A, Hoxworth J, Yarboro C, Smolen JS, Steiner G, Rosen A, Zhang C, Menard HA, Zhou ZJ, Palosuo T, van Venrooij WJ, Wilder RL, Klippel JH, Schumacher HR, El-Gabalawy HS. Rheumatoid arthritis associated autoantibodies in patients with synovitis of recent onset. Arthritis Res 2000;2:236-43.

Haas JP, Truckenbrodt H, Hoza CPJ, Scholz S, Albert ED. Subtypes of HLA-DRB1*03, *08, *11, $* 12$, $* 13$ and $* 14$ in early onset pauciarticular juvenile chronic arthritis (EOPA) with and without iridocyclitis. Clin Exp Rheumatol 1994;12(suppl 10):S7-S14. 
Hakala M, Pöllänen R, Nieminen P. The ARA revised criteria select patients with clinical rheumatoid arthritis from a population based cohort of subjects with chronic rheumatic diseases registered for drug reimbursement. J Rheumatol 1993;20:1674-8.

Hemady RK, Baer JC, Foster CS. Immunosuppressive drugs in the management of progressive corticosteroid-resistant uveitis associated with juvenile rheumatoid arthritis. Int Ophthalmol Clin 1992;32:241-52.

Henderly DE, Genstler AJ, Smith RE, Rao NA. Changing patterns of uveitis. Am J Ophthalmol 1987;103:131-6.

Huhtinen M, Karma A. HLA B27 typing in the categorization of uveitis in a HLA B27 rich population. Br J Ophthalmol 2000;84:413-16.

Jabs DA, Rosenbaum JT, Foster CS, Holland GN, Jaffe GJ, Louie JS, Nussenblatt RB, Stiehm ER, Tessler H, van Gelder RN, Whitcup SN,Youcum D. Perspective: Guidelines for the use of immunosuppressive drugs in patients with ocular inflammatory diseases: recommendations of an expert panel. Am J Ophthalmol 2000;130:492-513.

John M, John V. Die Prognose der juvenilen chronischen Arthritis. Eine Studie an 296 Patienten. Aktuelle Rheumatologie 1984;9:159-64.

Kaipiainen-Seppänen O, Savolainen A. Incidence of chronic juvenile rheumatic diseases in Finland during 1980-1990. Clin Exp Rheumatol 1996;14:441-4.

Kaipiainen-Seppänen O, Savolainen A. Changes in the incidence of juvenile rheumatoid arthritis in Finland. Rheumatology 2001;20:

Kanski JJ. Anterior uveitis in juvenile rheumatoid arthritis. Arch Ophthalmol 1977;95:1794-7.

Kanski JJ. Care of children with anterior uveitis. Trans Ophthalmol Soc UK 1981;101:387-90.

Kanski JJ. Uveitis in juvenile chronic arthritis: incidence, clinical features and prognosis. Eye 1988;2:641-5

Kanski JJ. Screening for uveitis in juvenile chronic arthritis. Br J Ophthalmol 1989;73:225-8.

Kanski JJ. Juvenile arthritis and uveitis. Surv Ophthalmol 1990;34:253-67.

Kanski JJ. Treatment of uveitis. In: Kanski JJ. Clinical Ophthalmology, 4.ed. Oxford, Butterworth-Heinemann 1999:317-9. 
Kanski JJ, Petty RE. Chronic childhood arthritis and uveitis. In Pepose JS, Holland GN, Wilhelmus KR, eds. Ocular infection and immunity, St Louis Mosby 1996:485-93.

Kanski JJ, Shun-Shin GA. Systemic uveitis syndromes in childhood: An analysis of 340 cases. Ophthalmology 1984;91:1147-51.

Kittles RA, Perola M, Peltonen L, Bergen AW, Aragon RA, Virkkunen M, Linnoila M, Goldman D, Long JC. Dual origins of Finns revealed by y chromosome haplotype variation. Am J Hum Genet 1998;62:1171-9.

Klemi PJ, Sorsa S, Happonen RP. Fine-needle aspiration biopsy from subcutaneous fat. An easy way to diagnose secondary amyloidosis. Scand J Rheumatol 1987;16:429-31.

Kotaniemi A. Growth retardation and bone loss as determinants of axial osteopenia in juvenile chronic arthritis. Scand J Rheumatol 1997;26:14-18.

Kunnamo I, Kallio P, Pelkonen P. Incidence of arthritis in urban Finnish children. A prospective study. Arthritis Rheum 1986;29:1232-8.

Laaksonen A. A prognostic study of juvenile rheumatoid arthritis. Acta Pediatr Scand 1966;55 (suppl 166):1-163.

Lantto R, von Wendt L. Juvenile rheumatoid arthritis in Northern Finland. Abstracts of the $2^{\text {nd }}$ International Symposium on Inflammatory Connective Tissue Diseases in Childhood and Adolescence. Prague. 1985.

Lawrence JM III, Moore TL, Osborn TG, Nesher G, Madson KL, Kinsella MB. Autoantibody studies in juvenile rheumatoid arthritis. Semin Arthritis Rheum 1993;22:265-74.

Leak AM. Autoantibody profile in juvenile chronic arthritis. Ann Rheum Dis 1988;47:178-82.

Leak AM, Ansell BM, Burman SJ. Antinuclear antibody studies in juvenile chronic arthritis. Arch Dis Child 1986;61:168-72.

Malagon C, van Kerckhove C, Giannini EH, Taylor J, Lovell DJ, Levinson JE, Passo MH, Ginsberg J, Burke MJ, Glass DN. The iridocyclitis of early onset pauciarticular juvenile rheumatoid arthritis: outcome in immunogenetically characterized patients. J Rheumatol 1992;19:160-3. 
McCannel CA, Holland GN, Helm CJ, Cornell PJ, Winston JF, Gordon Rimmer T, UCLA Community-based Uveitis Study Group. Causes of uveitis in the general practice of ophthalmology. Am J Ophthalmol 1996;121:35-46

Melin-Aldana H, Giannini EH, Taylor J, Lovell DJ, Levinson JE, Passo MH, Ginsberg J, Burke MJ, Glass DN. Human leukocyte antigen-DRB1*1104 in the chronic iridocyclitis of pauciarticular juvenile rheumatoid arthritis. J Pediatr 1992;121:56-60.

Mercanti A, Parolini B, Bonora A, Lequaglie Q, Tomazzoli L. Epidemiology of endogenous uveitis in north-eastern Italy. Analysis of 655 new cases. Acta Ophthalmol Scand 2001;79:64-8.

Michels H, Häfner R, Morhart R, Schuchmann L, Truckenbrodt H. Five year follow-up of a prospective cohort of juvenile chronic arthritis with recent onset. Clin Rheumatol 1987;2:87-92.

Miettinen R. Incidence of uveitis in northern Finland. Acta Ophthalmol 1977;55:252-60.

Moe N, Rygg M. Epidemiology of juvenile chronic arthritis in northern Norway: A ten-year retrospective study. Clin Exp Rheumatol 1998;16:99-101.

Moroldo MB, Tague BL, Shear ES, Glass DN, Giannini EH. Juvenile rheumatoid arthritis in affected sibpairs. Arthritis Rheum 1997;40:1962-6.

Murray KJ, Moroldo MB, Donnelly P, Prahalad S, Passo MH, Giannini EH, Glass DN. Agespecific effects of juvenile rheumatoid arthritis-associated HLA alleles. Arthritis Rheum 1999;42:1843-53.

Myllykangas-Luosujärvi R, Aho K, Kautiainen H, Isomäki H. Shortening of life span and causes of excess mortality in a population-based series of subjects with rheumatoid arthritis. Clin Exp Rheumatol 1995;13:149-53.

Nei M, Roychoudhury AK. Genetic relationship and evolution of human races. In: Heckt MK, Wallace B, Prance GT, eds. Evolutionary Biology. New York: Plenum, 1982:1-59.

Nguyen QD, Foster CS. Saving the vision of children with juvenile rheumatoid arthritisassociated uveitis. JAMA 1998;280:1133-4.

Nussenblatt RB, Palestine AG, Chan CC, Stevens G Jr, Mellow SD, Breen SB. Randomised, double-masked study of cyclosporine compared to prednisolone in the treatment of endogenous uveitis. Am J Ophthalmol 1991;112:138-46. 
Nussenblatt RB, Whitcup SM, Palestine AG. Uveitis: Fundamentals and clinical practice. 2nd ed., St. Louis, Mosby Year Book, 1996.

O'Brien JM, Albert DM, Foster CS. Juvenile rheumatoid arthritis. In: Albert DM, Jakobiec FA, eds. Principles and practice of ophthalmology: Clinical Practice. Vol. 5. Philadelphia: W.B. Saunders Co., 1994:2873-87.

O'Connor GR. Current classification of uveitis. In: Saari KM, ed. Uveitis update. Amsterdam: Elsevier 1984:3-6.

Oen KG, Cheang M. Epidemiology of chronic arthritis in childhood. Semin Arthritis Rheum 1996;26:575-91.

Ohm J. Bandfoermige Hornhauttruebung bei einem neunjaehrigen Maedchen und ihre Behandlung mit subconjunctivalen Jodkaliumeinspritzungen. Klin Monatsbl Augenheilk 1910;48:243-6.

Ohno S, Char DH, Kimura SJ, O'Connor GR. HLA antigens and antinuclear antibody titres in juvenile chronic iridocyclitis. Br J Ophthalmol 1977;61:59-61.

Perkins ES. Patterns of uveitis in children. Br J Ophthalmol 1966;50:169-85.

Petty RE, Hunt DW, Rollins DF, Schroeder ML, Puterman ML. Immunity to soluble retinal antigen in patients with uveitis accompanying juvenile rheumatoid arthritis. Arthritis Rheum 1987;30:287-93.

Petty RE, Southwood TR. Revision of the proposed classification criteria for juvenile idiopathic arthritis: Durban, 1997. J Rheumatol 1998;25:1991-4.

Pivetti-Pezzi P. Uveitis in children. Eur J Ophthalmol 1996;6:299-306.

Pritchard MH, Matthews N, Munro J. Antibodies to influenza A in a cluster of children with juvenile chronic arthritis. Br J Rheumatol 1988;27:176-80.

Päivönsalo-Hietanen T, Tuominen J, Vaahtoranta-Lehtonen H, Saari KM. Incidence and prevalence of different uveitis entities in Finland. Acta Ophthalmol Scand 1997;75:76-81.

Päivönsalo-Hietanen T, Tuominen J, Saari KM. Uveitis in children: Population-based study in Finland. Acta Ophthalmol Scand 2000;78:84-8. 
Rao NA, Foster DJ. General approach to the uveitis patient. In: Textbook of Ophthalmology, The uvea, Podos SM, Yanoff M, eds, vol 2, Gower Medical Publishing, New York, London. 1992:117.

Rao NA, Forster DJ, Spalton DJ. Anterior uveitis. In: Textbook of Ophthalmology: The uvea. Podos and Yanoff, eds., vol 2, Gover Medical Publishing, New York, London. 1992: 1-19.

Reiff A, Takei S, Sadeghi S, Stout A, Shaham B, Bernstein B, Gallagher K, Stout T. Etanercept therapy in children with treatment-resistant uveitis. Arthritis Rheum 2001;44:1411-15.

Rodriguez A, Akova YA, Pedroza-Seres M, Foster CS. Posterior segment ocular manifestations in patients with HLA-B27-associated uveitis. Ophthalmology 1994;101:1267-74.

Rodriguez A, Calonge M, Pedroza-Seres M, Akova YA, Messmer EM, D'Amico DJ, Foster CS. Referral patterns of uveitis in a tertiary eye care center. Arch Ophthalmol 1996;114:593-9.

Rosenbaum JT. Uveitis. An internist's view. Arch Intern Med 1989;149:1173-6.

Rosenbaum JT. Characterization of uveitis associated with spondyloarthritis. J Rheumatol $1989 ; 16: 792-6$.

Rosenbaum JT. An algorithm for the systemic evaluation of patients with uveitis: guidelines for the consultant. Semin Arthritis Rheum 1990;19:248-57.

Rosenbaum JT. Treatment of severe refractory uveitis with intravenous cyclophosphamide. J Rheumatol 1994;21:123-5.

Rosenbaum JT, Cousins SW. Uveitis and arthritis: Experimental models and clinical correlates. Semin Arthritis Rheum 1982;11:383-9.

Rosenbaum JT, George RK, Gordon C. The treatment of refractory uveitis with intravenous immunoglobulin. Am J Ophthalmol 1999;127:545-9.

Rosenberg AM. Uveitis associated with juvenile rheumatoid arthritis. Semin Arthritis Rheum $1987 ; 16: 158-73$.

Rosenberg AM, Oen KG. The relationship between ocular and articular disease activity in children with juvenile rheumatoid arthritis and associated uveitis. Arthritis Rheum 1986;29:797800.

Rothova A, Buitenhuis HJ, Meenken C, Brinkman CJJ, Linssen A, Alberts C, Luyendijk 1, Kijlstra A. Uveitis and systemic disease. Br J Ophthalmol 1992;76:137-41. 
Rothova A, Suttorp-van Schulten MSA, Treffers WF, Kijlstra A. Causes and frequency of blindness in patients with intraocular inflammatory disease. Br J Ophthalmol 1996;80:332-6.

Rothova A, van Veenendaal WG, Linssen A, Glasius E, Kijlstra A, de Jong PTVM. Clinical features of acute anterior uveitis. Am J Ophthalmol 1987;103:137-45.

Saari KM. Acute anterior uveitis. In Saari KM, ed.: Uveitis update. Amsterdam: Excerpta Medica, 1984:79-90.

Savolainen A, Säilä H, Kotaniemi K, Kaipiainen-Seppänen O, Leirisalo-Repo M, Aho K. Magnitude of the genetic component in juvenile idiopathic arthritis. Ann Rheum Dis 2000;53:1001.

Savolainen A, Ylijoki H. Declining prevalence of secondary amyloidosis in JCA. Clin Exp Rheumatol 1995;13:551.

Savolainen HA. Chlorambucil in severe juvenile chronic arthritis: Longterm follow-up with special reference to amyloidosis. J Rheumatol 1999;26:898-903.

Savolainen HA, Isomäki HA. Decrease in the number of deaths from secondary amyloidosis in patients with juvenile rheumatoid arthritis. J Rheumatol 1993;20:1201-3.

Savolainen HA, Kautiainen H, Isomäki H, Aho K, Verronen P. Azathioprine in patients with juvenile chronic arthritis: a longterm follow-up study. J Rheumatol 1997;24:2444-50.

Schaller JG, Johnson GD, Holborow EJ, Ansell BM, Smiley WK. The association of antinuclear antibodies with the chronic iridocyclitis of juvenile rheumatoid arthritis (Still's disease). Arthritis Rheum 1974;17:409-16.

Schaller J, Kupfer C, Wedgewood RJ. Iridocyclitis in juvenile rheumatoid arthritis. Pediatrics 1969;44:92-100.

Schlaegel TF Jr. Granulomatous uveitis: An etiologic survey of 100 cases. Trans Am Acad Ophthalmol 1958;62:813-25.

Schlote T, Dannecker G, Thiel H-J, Zierhut M. Cyclosporin A in der Therapie der chronischen Uveitis im Kindesalter. Ophthalmologe 1996;93:745-8.

Shah SS, Lowder CY, Schmitt MA, Wilke WS, Kosmorsky DO, Meisler DM. Low-dose methotrexate therapy for ocular inflammatory disease. Ophthalmology 1992;99:1419-23. 
Sherry DD, Mellins ED, Wedgwood RJ. Decreasing severity of chronic uveitis in children with pauciarticular arthritis. Am J Dis Chil 1991:145:1026-8.

Silman AJ, Hochberg MC. Epidemiology of the rheumatic diseases. Oxford University Press: Oxford 1993.

Smiley WK. Iridocyclitis in Still's disease. Prognosis and steroid therapy. Trans Ophthalmol Soc UK 1965;85:351-6.

Smiley WK.The eye in juvenile rheumatoid arthritis. Trans Ophthalmol Soc UK 1974;94:817-29.

Smiley WK, May E, Bywaters EG. Ocular presentations of Still's disease and their treatment; iridocyclitis in Still's disease, its complications and treatment. Ann Rheum Dis 1957;16:371-83.

Smit RLMJ, Baarsma GS, de Vries J. Classification of 750 consecutive uveitis patients in the Rotterdam Eye Hospital. Int Ophthalmol 1993;17:71-75.

Spalter HF. The visual prognosis in juvenile rheumatoid arthritis. Trans Am Ophthalmol Soc 1975;3.554-70.

Steere AC, Malawista SE, Snydman DR, Shope RE, Andiman WA, Ross MR, Steele RM. Lyme arthritis. An epidemic of oligoarticular arthritis in children and adults in three Connecticut communities. Arthritis Rheum 1977;20:7-17.

Steward AJ, Hill BM. Ocular manifestations in juvenile rheumatoid arthritis. Can J Ophthalmol 1967;2:58-62.

Still GF. On a form of chronic joint disease in children. Med Chir Trans 1897;80:47-59. Republication Am J Dis Child 1978;132:195-200.

Stoeber E. Prognosis in juvenile chronic arthritis. Follow-up of 433 chronic rheumatic children. Eur J Pediatr 1981;135:225-8.

Suttorp-Schulten MSA, Rothova A. The possible impact of uveitis in blindness: a literature survey. Br J Ophthalmol 1996;80:844-8.

Säilä HM, Savolainen HA, Kotaniemi KM, Kaipiainen-Seppänen OA, Leirisalo-Repo MT, Aho KV. Juvenile idiopathic arthritis in multicase families. Clin Exp Rheumatol 2001;19:218-220.

Towner SR, Michet CJ Jr, O'Fallon NM, Nelson AM. The epidemiology of juvenile arthritis in Rochester, Minnesota 1960-1979. Arthritis Rheum 1983;26:1208-13. 
Tugal-Tutkun I, Havrlikova K, Power WJ, Foster CS. Changing patterns in uveitis of childhood. Ophthalmology 1996;103:375-83.

Vadot E, Barth E, Billet P. Epidemiology of uveitis - premilinary results of a prospective study in Savoy. In: Saari KM, ed. Uveitis update. Amsterdam: Excerpta Medica 1984:13-16.

Vesterdal E, Sury B. Iridocyclitis and bandshaped corneal opacity in juvenile rheumatoid arthritis. Acta Ophthalmol 1950;28:321-37.

Virtaranta-Knowles K, Sistonen P, Nevanlinna HR. A population genetic study in Finland: Comparison of the Finnish- and Swedish-speaking populations. Hum Hered 1991;41:248-64.

Vitale AT, Rodriguez A, Foster CS. Low-dose cyclosporin A therapy in treating chronic, noninfectious uveitis. Ophthalmology 1996;103:365-73.

Välimäki J, Airaksinen J, Tuulonen A. Molteno implantation for secondary glaucoma in juvenile rheumatoid arthritis. Arch Ophthalmol 1997;115:1253-6.

Wakefield D, Montanaro A, Mc Cluskey P. Acute anterior uveitis and HLA B27. Surv Ophthalmol 1991;36:223-32.

Weiss AH, Wallace CA, Sherry DD. Methotrexate for resistant chronic uveitis in children with juvenile rheumatoid arthritis. J Pediatr 1998;133:266-8.

Wolf MD, Lichter PR, Ragsdale CG. Prognostic factors in the uveitis of juvenile rheumatoid arthritis. Ophthalmology 1987;94:1242-8.

Woo P, Wedderburn LR. Juvenile chronic arthritis. Lancet 1998;351:969-73.

Wood PHN. Nomenclature and classification of arthritis in children. In: Munthe E, ed.: The care of rheumatic children. EULAR Monograph series No.3. EULAR Publishers, Basel 1978: 47-50.

Yancey C, White P, Magilavy D, Gewanter H, Lowe B, Passo M, Sherry D, Warren R, Gross RD, Fierson W, Koller H, Mahon K, Rabinowicz IM, Stager DR. Guidelines for ophthalmologic examinations in children with juvenile rheumatoid arthritis. Pediatrics 1993;92:295-6.

Ylijoki H. Re-evaluation of the factors determining the longterm clinical outcome of juvenile rheumatoid arthritis. (In Finnish with English summary) Turku: The Social Insurance Institution, Finland, Studies in social security and health 31, 1998:1-133

Youssef W, Russell AS. Cardiac, ocular, and renal manifestations of seronegative spondyloarthropathies. Curr Opin Rheumatol 1990;2:582-5. 
Zerjal T, Dashnyam B, Pandya A, Kayser M, Roewer L, Santos FR, Schiefenhövel W, Fretwell N, Jobling MA, Harihara S, Shimizu K, Semjidmaa D, Sajantila A, Salo P, Crawford MH, Ginter EK, Evgrafov OV, Tyler-Smith C. Genetic relationships of Asians and northern Europeans, revealed by y-chromosomal DNA analysis. Am J Hum Genet 1997;60:1174-83. 